\title{
Modeling and multi-objective optimization of an R450A vapor compression refrigeration system
}

\author{
Alireza Zendehboudi ${ }^{a^{*}}$, Adrián Mota-Babiloni ${ }^{\mathbf{b}}$, Pavel Makhnatch ${ }^{\mathrm{c}}, \mathbf{R}$. \\ Saidur $^{\mathrm{d}, \mathrm{e}}$, Sadiq M. Sait ${ }^{\mathrm{f}}$ \\ ${ }^{a}$ Department of Building Science, Tsinghua University, Beijing 100084, China \\ ${ }^{b}$ ISTENER Research Group, Department of Mechanical Engineering and Construction, Campus de Riu \\ Sec s/n, Universitat Jaume I, E-12071 Castellón de la Plana, Spain \\ ${ }^{c}$ Division of Applied Thermodynamics and Refrigeration, Department of Energy Technology, KTH Royal \\ Institute of Technology, Brinellvägen 68, 10044 Stockholm, Sweden \\ ${ }^{d}$ Research Centre for Nano-Materials and Energy Technology (RCNMET), School of Science and Technology, \\ Sunway University, Bandar Sunway, Petaling Jaya, 47500 Selangor Darul Ehsan, Malaysia \\ ${ }^{\mathrm{e}}$ CoRE-RE, Research Institute, King Fahd University of Petroleum \& Minerals, Dhahran, Saudi Arabia \\ ${ }^{f}$ CCITR-RI, King Fahd University of Petroleum \& Minerals, Dhahran, Saudi Arabia
}

\begin{abstract}
:
The main objective of this work is to comprehensively investigate R450A behavior in refrigeration systems and subsequently optimize the main operating variables for the first time to reach the maximum performance. For this purpose, a hybrid multi-objective optimization model coupling response surface method and non-dominated sorted genetic algorithm II is established. The regression analysis results reveal a good agreement of experimental data samples with the quadratic polynomial models with a coefficient of determination exceeding 0.97 . The optimum results for the first scenario indicate that the reduction in the motor-compressor electrical power consumption and discharge temperature is $19.72 \%$ and $54.21 \%$, respectively, and percentage of growth in the refrigerant mass flow rate is $230.52 \%$ when the middle evaporator temperature, middle condenser temperature, superheating degree, and subcooling degree change from $-14.95{ }^{\circ} \mathrm{C}$ to $8.71{ }^{\circ} \mathrm{C}, 31.28{ }^{\circ} \mathrm{C}$ to $24.50{ }^{\circ} \mathrm{C}, 13.12 \mathrm{~K}$ to $10.49 \mathrm{~K}$, and $15.65 \mathrm{~K}$ to $15.66 \mathrm{~K}$, respectively.
\end{abstract}

Keywords: Vapor compression system, Zeotropic refrigerant, Response surface method, Central composite design, Multi-objective optimization.

\footnotetext{
*Corresponding author: Email address: a-115@mails.tsinghua.edu.cn (Alireza Zendehboudi); Tell: +86-13141341897
} 


\section{Nomenclature}

$\begin{array}{ll}\text { ANOVA } & \text { analysis of variance } \\ \mathrm{b}_{0} & \text { constant coefficient } \\ \mathrm{b}_{\mathrm{i}} & \text { linear coefficient } \\ \mathrm{b}_{\mathrm{ii}} & \text { quadratic coefficient } \\ \mathrm{b}_{\mathrm{ij}} & \text { cross-interaction coefficient } \\ \text { COP } & \text { coefficient of performance } \\ \mathrm{m}_{\text {ref }} & \text { mass flow rate }\left(\mathrm{g} \mathrm{s}{ }^{-1}\right) \\ \text { NSGA II } & \text { non-dominated sorted genetic algorithm II } \\ \mathrm{P}_{\text {comp }} & \text { motor-compressor electrical power consumption }(\mathrm{W}) \\ \mathrm{Q}_{\text {evap }} & \text { cooling capacity }(\mathrm{W}) \\ \mathrm{R}^{2} & \text { determination coefficient } \\ \mathrm{SCD} & \text { subcooling degree }(\mathrm{K}) \\ \mathrm{SHD} & \text { superheating degree }(\mathrm{K}) \\ \mathrm{T} & \text { temperature }\left({ }^{\circ} \mathrm{C}\right) \\ \mathrm{x}_{\mathrm{i}} & \text { independent variable } \\ \mathrm{y} & \text { response } \\ \hat{\mathrm{y}} & \text { estimated response }\end{array}$

\section{Greek symbols}

$\varepsilon$

error in response

\section{Subscripts}

c

condenser

dis discharge

evap evaporator

ref refrigerant

\section{Abbreviations}

CCD central composite design

GA genetic algorithm

GWP global warming potential

HFC hydrofluorocarbons

HFO hydrofluoroolefines

RSM response surface method 


\section{Introduction}

The rapid development of human population and buildings has caused an increasing demand for air conditioning systems in order to satisfy cooling requirements and level of comfort in buildings. For example, less than $1 \%$ of urban Chinese households owned an air conditioner in 1990, while this number increased to almost 100\% by 2009 (표, 2015). However, the air conditioning systems utilize around $30 \%$ of the total electricity consumption in the


IPCC (2014) estimates that energy demand for residential air conditioning in the summer is projected to increase over 13 -fold between 2000 and 2050 and over 30 -fold by 2100 . On the other hand, the air conditioning plays an important role in the context of climate change and the associated increase of ambient temperatures. R134a, with a high global warming potential (GWP) of 1300, is used worldwide in air conditioning systems (Simmonds et al., 2015; Wu et al., 2018). As a result, R134a has become a dominant contributor to global warming among all the HFCs (Myhre et al., 2013). Given the high number of R134a units still in operation, it is required that they be phased-out in the coming years to contribute to the goal of the international climate agreement to avoid a $0.5^{\circ} \mathrm{C}$ increase of the global mean surface temperature by 2100 (UNEP, 2016). Therefore, environmental and performance problems associated with the operation of such systems emphasize the need for the development of air conditioning systems to increase their performance.

Mixtures of hydrofluoroolefines (HFOs) and hydrofluorocarbons (HFCs) have been considered to be a possible trade-off solution to replace widely extended HFCs like R134a, $\mathrm{R} 404 \mathrm{~A}$, or R410A. This is to mitigate the greenhouse gas emissions from refrigeration and air conditioning systems (Domanski et al., 2017). According to the analysis of the thermodynamic properties, some of these new mixtures are seen as good alternatives to the HFCs (Devecioğlu and Oruc, 2015). A number of drop-in and retrofit experimental tests have been performed 
during the past years to improve the knowledge of the behavior of these fluids in real operation (Mota-Babiloni et al., 2017).

R450A, with a relatively low GWP of 547 , is an $\mathrm{HFO} / \mathrm{HFC}$ mixture that appears as non-flammable and low toxicity (A1) alternative to R134a because of the comparable characteristics in thermodynamic properties, safety classification, operating pressures and materials, and lubricant oil compatibility. Both have been compared in some refrigeration system constructions. In a medium capacity refrigeration system equipped with a variablespeed compressor and shell and tube heat exchangers, R450A showed a small drop in cooling capacity but comparable energy performance (Mota-Babiloni et al., 2015). Makhnatch et al. (2017) evaluated the performance of this refrigerant in a small capacity refrigeration system equipped with a rotatory compressor and plate heat exchanger. Their results indicated a $7.9 \%$ reduction in average compressor power consumption and $2.9 \%$ reduction in coefficient of performance (COP) for R450A when compared to R134a. Electric energy consumption with R450A was between $1.3 \%$ and $5.8 \%$ higher than that of R134a in a single-stage refrigeration system with a semi-hermetic compressor connected to a commercial vertical cabinet with doors placed inside a climatic chamber (lopis et al., 2017). Additionally, Kedzierski and Kang (2018) studied the local convective boiling heat transfer in micro-fin tubes resulting, on an average, $15 \%$ lower for R450A in comparison with R134a.

Although laboratory work provides a beneficial point of view from the operation of these systems using R450A, this method is time intensive and also is often limited to the available test equipment. Additionally, it cannot provide a comprehensive vision of an R450A vapor compression refrigeration system under different operational conditions and offer predictive capabilities that allow for a cheaper and faster scanning of this system to promote understanding. The restrictions on laboratory tests require scholars to develop reliable models that can predict or simulate the operation of $\mathrm{R} 450 \mathrm{~A}$ vapor compression refrigeration systems. 
Recently, Mendoza-Miranda et al. (2016a) developed a shell-and-micro-fin tube evaporator model that predicts evaporating pressure, two-phase overall heat transfer coefficient, and cooling capacity fitted within $\pm 10 \%$ to the experimental data. In another work, MendozaMiranda et al. (2016b) applied the Buckingham $\pi$-theorem to predict the compressor efficiencies in a variable speed reciprocating compressor in order to calculate the operating and energetic parameters of the refrigeration system. Energetic parameters for R450A have been modeled using artificial neural networks and validated using cross-validation technique, producing minimum relative errors 0.15 for the cooling capacity and the coefficient of performance (Belman-Flores et al., 2017).

From the above results, R450A seems to be a promising solution as a drop-in replacement to R134a in refrigeration systems. Even though it has been recently commercialized, the knowledge about its behavior is still limited. The design and operation of the refrigeration units involve performing trade-offs between different objective functions at different values of input variables, which must be optimized for the specific purpose of R450A refrigerant application scenario. When R450A is used instead of R134a, the cooling capacity and electric power consumption values decrease, which results in a decrease in COP (Makhnatch et al., 2017). Therefore, the question on how to further improve the performance of the R450A vapor compression refrigeration systems still needs to be addressed. Hence, before the extension to the utilization of R450A, an efficient computational framework is required to define its optimum performance to enhance the total system energy performance. The traditional one-variable-at-a-time optimization process considers factors separately and determines their effects on output parameters. This process is time-consuming and insufficient as it does not include the interactive effects among the factors studied. Response surface method is a relevant approach to address the limitations of laboratory works and to evaluate the performance of these systems. Response surface method consists of a set of statistical and 
mathematical techniques that are useful for modeling, optimizing, and determining the effects of multiple independent variables on dependent ones and the interactive effects between them. Moreover, the response surface method provides optimization process with a limited number of experimental data. So far, response surface method has been successfully applied in the fields of refrigeration (Liu et al., 2015; Mahmoudi et al., 2016), renewable energy (Bendato et

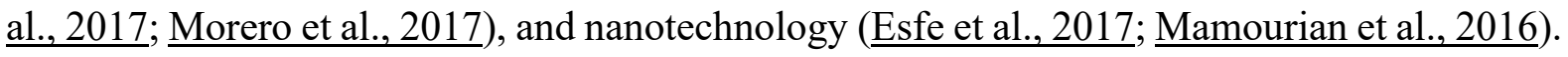
Owing to the direct relationship between the motor-compressor electrical power consumption, cooling capacity, discharge temperature, and refrigerant mass flow rate in R450A vapor compression refrigeration systems, it is useful to consider objectives simultaneously to perform a multi-objective optimization. Combination of response surface method and non-dominated sorted genetic algorithm II allows generating comprehensive information, establishing predictive models, and determining the best possible trade-offs between the conflicting objectives in R450A vapor compression refrigeration systems. The results by this hybrid framework would lead to a better understanding of different influential parameters on this system, which can subsequently be utilized to design, optimize, and enhance the thermal performance of refrigeration units using R450A.

As of now, no available literature discusses the implementation of response surface method in vapor compression refrigeration systems, or, studies on multi-objective optimization based on evolutionary algorithms for such a complex system. Consequently, the aim of this paper is to improve the understanding of refrigeration units using R450A by comprehensively investigating the effects of design variables on the performance of such systems and subsequently optimize them to aid refrigeration engineers to enhance its performance. Therefore, in this work modeling and experimental validation is performed by central composite design (CCD) and response surface method (RSM). The models include the effects of the middle evaporator temperature $\left(T_{\text {evap }}\right)$, middle condenser temperature $\left(T_{c}\right)$, superheating 
degree (SHD), and subcooling degree (SCD). The effects of each operating parameter and their interactive effects on the motor-compressor electrical power consumption $\left(\mathrm{P}_{\text {comp }}\right)$, cooling capacity $\left(\mathrm{Q}_{\text {evap }}\right)$, coefficient of performance $(\mathrm{COP})$, discharge temperature $\left(\mathrm{T}_{\mathrm{dis}}\right)$, and refrigerant mass flow rate $\left(\mathrm{m}_{\mathrm{ref}}\right)$ are also analyzed in depth. Subsequently, a fastelitist nondominated sorted genetic algorithm II (NSGA II) based multi-objective optimization is linked to models developed by RSM to optimize the R450A system and provide the best design parameters by considering two different scenarios.

\section{Materials and methods}

\subsection{Experimental facility}

The experimental data required for the modeling aspect is extracted from Makhnatch et al. (2017). The experimental setup is based on a small capacity refrigeration system as shown in Figure 1. The compressor is a fully hermetic rotary type with a motor rating of $550 \mathrm{~W}$ nominal power and displacement of $15.44 \mathrm{~cm}^{3}$ per revolution, both evaporator and condenser are plate heat exchangers, and the expansion valve is an $\mathrm{R} 134 \mathrm{a}$ designed thermostatic expansion valve. The evaporator is controlled by a closed loop of $43 \mathrm{wt} \%$ ethylene glycol based secondary refrigerant and the condenser by an open loop of tap water whose flow rate is set by water regulating valve. 


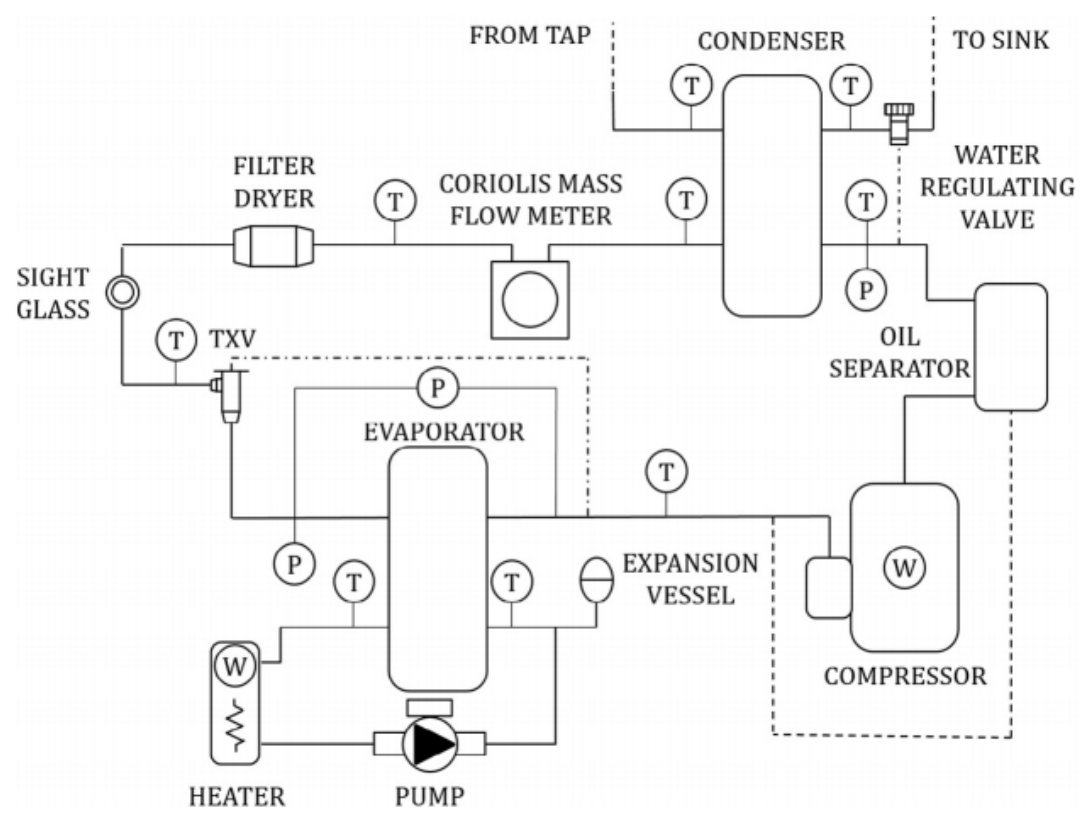

Figure 1. Experimental setup and measuring sensors (Makhnatch et al., 2017).

The experimental data range is obtained from 36 steady-state tests using the $\mathrm{HFO} / \mathrm{HFC}$ mixture R450A, varying the middle evaporating temperatures between -15 and $12.5^{\circ} \mathrm{C}$; and the middle condensing temperatures between 25 and $35{ }^{\circ} \mathrm{C}$. The average measured superheating and subcooling degrees are $12.1 \mathrm{~K}$ and $11.2 \mathrm{~K}$, respectively. To obtain the thermodynamic states of the refrigerant in the cycle, T-type thermocouples with $\pm 0.11 \mathrm{~K}$ uncertainty are used to measure the temperatures at the inlet and outlet of each main component. Two pressure transducers with $\pm 0.08 \%$ uncertainty are used to determine the condensation and evaporation pressure. A differential pressure sensor with $0.25 \%$ uncertainty is installed to account for measuring the refrigerant pressure difference between evaporator inlet and outlet, and a Coriolis type flow meter with $\pm 0.5 \%$ uncertainty is used to measure the refrigerant mass flow. Two configurable multi-transducer measures the electric power use of motor-compressor and the heaters with $\pm 0.2 \%$ uncertainty. 


\subsection{Response surface method}

RSM consists of a group of statistical and mathematical techniques for establishing empirical models to understand the interactive effects among the factors that need to be optimized (Box and Wilson, 1951). Using the experimental data, RSM's objective is to establish a suitable relation between a response or output parameter to the levels of a number of independent or input parameters to clarify the relationship and interaction between them (Makela, 2017). For this concrete application, the relationship between the independent variables such as $\mathrm{T}_{\text {evap }}, \mathrm{T}_{\mathrm{c}}, \mathrm{SHD}, \mathrm{SCD}$, and response $y$, can be formulated as shown in Equation (1).

$$
\hat{\mathrm{y}}=\mathrm{f}\left(\mathrm{T}_{\text {evap }}, \mathrm{T}_{\mathrm{c}}, \mathrm{SHD}, \mathrm{SCD}\right)+\varepsilon
$$

where $\hat{y}$ is the estimated response and $\varepsilon$ is the error in the response. A mathematical equation is fitted to represent the response characteristics by establishing a map between the set of independent parameters and the response. The simplest model which can be implemented in RSM is based on a linear function, which is given as (Box and Wilson, 1951),

$$
\hat{\mathrm{y}}=\mathrm{b}_{0}+\sum_{\mathrm{i}=1}^{\mathrm{z}} \mathrm{b}_{\mathrm{i}} \mathrm{x}_{\mathrm{i}}
$$

If the first-order model is insignificant as a result of curvature, a two-factor interaction model or quadratic polynomial model is used to fit the data to find critical points. The twofactor interaction model to approximate the function $\mathrm{f}$ can be written as follows (Box and Wilson, 1951):

$$
\hat{y}=b_{0}+\sum_{i=1}^{z} b_{i} x_{i}+\sum_{j>i}^{z} b_{i j} x_{i} x_{j}
$$


Quadratic polynomial model is explained as a sum of all linear, cross-interaction, and self-interaction terms between predictors. Thus, the approximating function can be written as in Equation (4) (Box and Wilson, 1951),

$$
\hat{\mathrm{y}}=\mathrm{b}_{0}+\sum_{\mathrm{i}=1}^{\mathrm{z}} \mathrm{b}_{\mathrm{i}} \mathrm{X}_{\mathrm{i}}+\sum_{\mathrm{i}=1}^{\mathrm{z}} \mathrm{b}_{\mathrm{ii}} \mathrm{x}_{\mathrm{i}}^{2}+\sum_{\mathrm{i}=1}^{\mathrm{z}} \sum_{\mathrm{j}>1} \mathrm{~b}_{\mathrm{ij}} \mathrm{X}_{\mathrm{i}} \mathrm{X}_{\mathrm{j}}
$$

The coefficients in the quadratic polynomial model are determined by solving the linear model $\mathrm{Y}=\mathrm{XB}$, depicted in Equations (5) and (6) (Box and Wilson, 1951).

$$
\begin{aligned}
\mathrm{Y}=\left(\begin{array}{c}
\mathrm{f}\left(\mathrm{x}^{1}\right) \\
\mathrm{f}\left(\mathrm{x}^{2}\right) \\
\vdots \\
\mathrm{f}\left(\mathrm{x}^{\mathrm{n}}\right)
\end{array}\right), \mathrm{X}=\left(\begin{array}{ccccccccccc}
1 & \mathrm{x}_{1}^{1} & \cdots & \mathrm{x}_{\mathrm{z}}^{1} & \left(\mathrm{x}_{1}^{1}\right)^{2} & \cdots & \left(\mathrm{x}_{\mathrm{z}}^{1}\right)^{2} & \mathrm{x}_{1}^{1} \mathrm{x}_{2}^{1} & \mathrm{x}_{1}^{1} \mathrm{x}_{3}^{1} & \cdots & \mathrm{x}_{\mathrm{z}-1}^{1} \mathrm{x}_{\mathrm{z}}^{1} \\
1 & \mathrm{x}_{1}^{2} & \cdots & \mathrm{x}_{\mathrm{z}}^{2} & \left(\mathrm{x}_{1}^{2}\right)^{2} & \cdots & \left(\mathrm{x}_{\mathrm{z}}^{2}\right)^{2} & \mathrm{x}_{1}^{2} \mathrm{x}_{2}^{2} & \mathrm{x}_{1}^{2} \mathrm{x}_{3}^{2} & \cdots & \mathrm{x}_{\mathrm{z}-1}^{2} \mathrm{x}_{\mathrm{z}}^{2} \\
1 & \vdots & \cdots & \vdots & \vdots & & \vdots & \vdots & \vdots & & \vdots \\
1 & \mathrm{x}_{1}^{\mathrm{n}} & \cdots & \mathrm{x}_{\mathrm{z}}^{\mathrm{n}} & \left(\mathrm{x}_{1}^{\mathrm{n}}\right)^{2} & \cdots & \left(\mathrm{x}_{\mathrm{z}}^{\mathrm{n}}\right)^{2} & \mathrm{x}_{1}^{\mathrm{n}} \mathrm{x}_{2}^{\mathrm{n}} & \mathrm{x}_{1}^{\mathrm{n}} \mathrm{x}_{3}^{\mathrm{n}} & \cdots & \mathrm{x}_{\mathrm{z}-1}^{\mathrm{n}} \mathrm{x}_{\mathrm{z}}^{\mathrm{n}}
\end{array}\right) \\
\mathrm{B}=\left(\mathrm{b}_{0}, \mathrm{~b}_{1}, \ldots, \mathrm{b}_{\mathrm{z}}, \mathrm{b}_{11}, \ldots, \mathrm{b}_{\mathrm{zz}}, \mathrm{b}_{12}, \mathrm{~b}_{13}, \cdots, \mathrm{b}_{\mathrm{p}-1, \mathrm{p}}\right)^{\mathrm{T}}
\end{aligned}
$$

The final solution is given by $\hat{\mathrm{B}}=\left(\mathrm{X}^{\prime} \mathrm{X}\right)^{-1} \mathrm{X}^{\prime} \mathrm{Y}$, where $\hat{y}$ is the estimated response, $b_{0}$ is the constant coefficient, $b_{i}$ is the linear coefficient of the independent variables $x_{i}, b_{i j}$ is the different cross-interaction coefficient between the input factor $x_{i}$ and $x_{j}$, and $b_{i i}$ is the ith quadratic coefficient of the input factor $x_{i}$ (Meyer et al., 2016).

The most well-known response surface method design is central composite design (Jensen, 1995). In central composite design, all point descriptions will be regarding the coded values of the factors. A central composite design comprises three group of design points: (i) fractional factorial design points, which allow prediction of the linear and cross-interaction terms; (ii) axial points, which are points that have all of the factors set to 0 , except one factor that has the value $\pm \alpha$ for efficient prediction of the self-interaction terms; and (iii) central points, which are points with all levels set to coded level 0 that give information about the presence of curvature in the response (Figure 2). Hence, the regular central composite design 
requires five levels of each factor: $-\alpha,+\alpha,-1,1$, and 0 . Considering $z$ as the number of independent variables, the design consists of a matrix from central points $(0,0, \ldots, 0)$, a matrix from factorial points $( \pm 1, \pm 1, \ldots, \pm 1)$, and a matrix from axial points of the form $( \pm \alpha, 0, \ldots, 0)$, $(0, \pm \alpha, \ldots, 0)$. The axial matrix is represented as in Equation (7) (Jensen, 1995).

$$
\mathrm{K}=\left[\begin{array}{ccccccc}
\alpha & 0 & 0 & \cdots & \cdots & \cdots & 0 \\
-\alpha & 0 & 0 & \cdots & \cdots & \cdots & 0 \\
0 & \alpha & 0 & \cdots & \cdots & \cdots & 0 \\
0 & -\alpha & 0 & \cdots & \cdots & \cdots & 0 \\
\vdots & & & & & & \vdots \\
0 & 0 & 0 & 0 & \cdots & \cdots & \alpha \\
0 & 0 & 0 & 0 & \cdots & \cdots & -\alpha
\end{array}\right]
$$

The value of $\alpha$ is calculated depending on orthogonality and rotatability of the design (Myers, 1971). Rotatable designs allow constant estimation variance at all points that are equidistant from the design centre. Therefore, if $\mathrm{N}$ denotes the number of factorial points, the value of $\alpha$ for a rotatable design is determined by Equation (8) (Box and Hunter, 1957).

$$
\alpha=(N)^{1 / 4}
$$

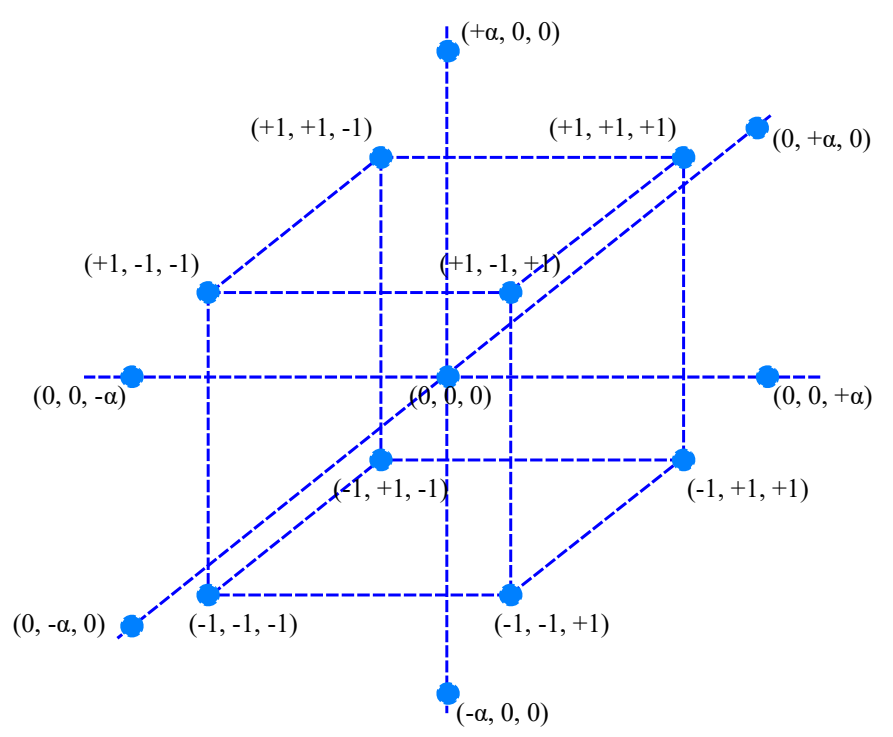

Figure 2. Central composite design. 


\subsection{Multi-objective genetic algorithm}

Genetic algorithm (GA) is a programming technique that uses evolutionary rules to solve optimization problems. In problem-solving via genetic algorithm, a certain number of potential solutions, also known as individuals, represented by structures called chromosomes, are considered as the initial population instead of the single points. The individuals are modified using different operators known as crossover and mutation, and a subset of the newly generated solutions called offsprints are reconsidered as initial solutions for the next generation (Goldberg, 1989). NSGA II developed by Deb et al. (2002) is an effective method to solve multiobjective optimization problems by simultaneously considering several objectives. Figure 3 indicates a flowchart of this algorithm. Generally, objective functions conflict with each other and a trade-off should be made when considering more than one target at the same time, since the realization of one objective causes failure of another.

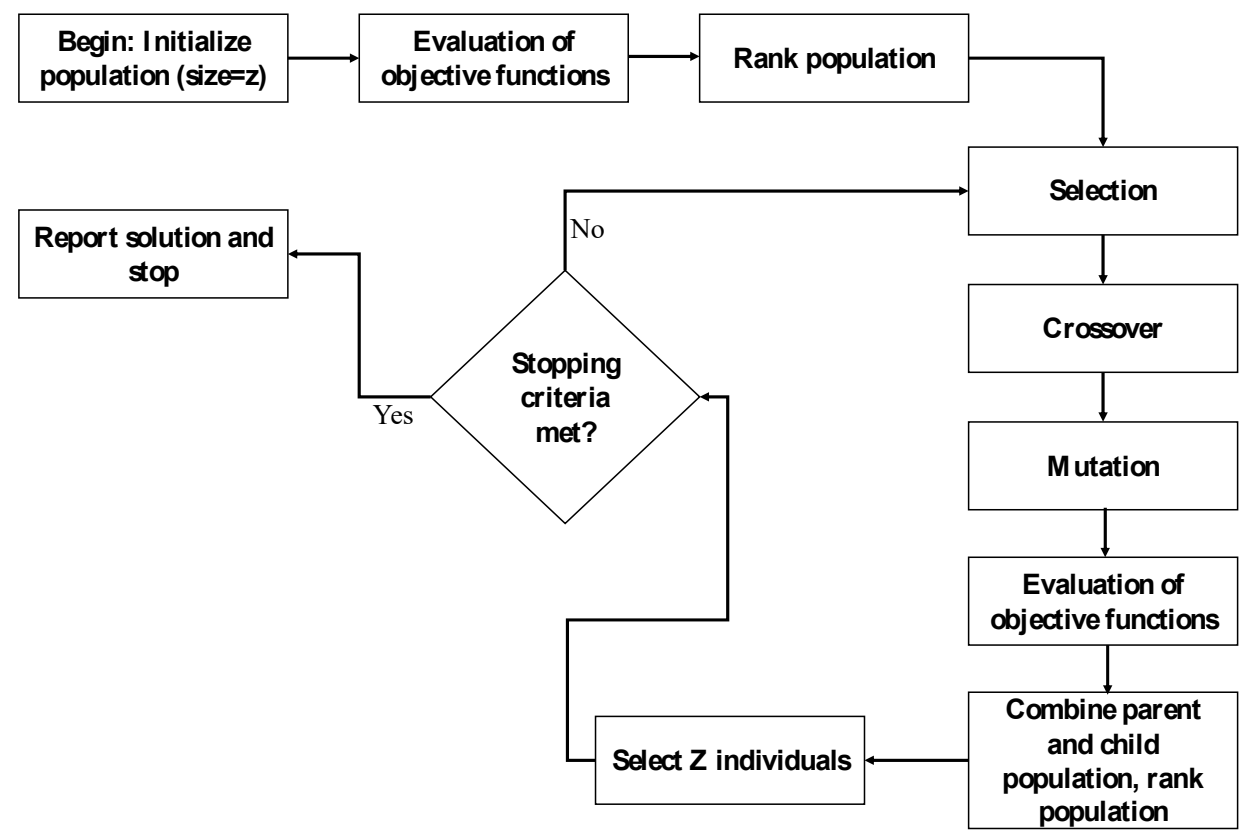

Figure 3. Flowchart of NSGA II.

\subsection{Problem formulation}

In this study, two different scenarios are considered in the multi-objective optimization process for the R450A vapor compression refrigeration system. In the first scenario, a multi- 
objective optimization algorithm is employed to minimize the motor-compressor electrical power consumption and discharge temperature, and maximize the refrigerant mass flow rate simultaneously. The second scenario sets out to maximize the cooling capacity and refrigerant mass flow rate, and minimize discharge temperature simultaneously.

The motor-compressor electrical power consumption, cooling capacity, discharge temperature, and refrigerant mass flow rate objective functions are achieved with the help of experimental data and regression models using response surface method. For this purpose, four influential variables including $\mathrm{T}_{\text {evap }}, \mathrm{T}_{\mathrm{c}}, \mathrm{SHD}$, and $\mathrm{SCD}$ are intended as optimization variables.

The multi-objective optimization problem generally can be represented as indicated in Equation (9) (Rao, 1991).

$$
\left\{\begin{array}{r}
\text { Minimize / Maximize } \mathrm{M}_{\mathrm{i}}(\mathrm{x}) \quad \mathrm{i}=1,2, \ldots, \mathrm{f} \\
\text { subject to } \\
\mathrm{w}_{\mathrm{e}}(\mathrm{x})=0, \quad \mathrm{e}=1,2, \ldots ., \mathrm{E} \\
\mathrm{z}_{\mathrm{v}}(\mathrm{x}) \leq 0, \quad \mathrm{v}=1,2, \ldots, \mathrm{V} ;
\end{array}\right.
$$

In Equation (9), $f$ shows the number of objective functions, $x$ is the symbol of a vector of $n$ decision variables, and $w_{e}(x)=0$ and $z_{v}(x) \leq 0$ are system constraints.

\subsection{Decision-making in the multi-objective optimization}

The selection of the best non-dominated solution through the NSGA II multi-objective optimization method requires a decision-making process to determine which solution is better than others. In the current study, the technique for an order of preference by similarity to ideal solution (TOPSIS) decision maker is employed. TOPSIS approach is based on the concept that the chosen solution should have the shortest distance from the ideal solution and the longest 
distance from the non-ideal solution. In this method, the approach shown in Equation (10) is used to non-dimensionalize the objectives (Ahmadi et al., 2016).

$$
F_{i j}^{n}=\frac{F_{i j}}{\sqrt{\sum_{i=1}^{m}\left(F_{i j}\right)^{2}}}
$$

In Equation (10), $F$ is the objective, $i$ denotes the index for each point on Pareto front, $j$ represents the index for each objective and $m$ denotes the number of points on Pareto front. Then the distance of each point on Pareto front from the ideal and non-ideal points is obtained for selecting the final solution. These parameters can be mathematically described and calculated using Equations (11) and (12) (Ahmadi et al., 2016).

$$
\begin{gathered}
\mathrm{d}_{\text {ideal }}=\sqrt{\sum_{\mathrm{j}=1}^{\mathrm{n}}\left(\mathrm{F}_{\mathrm{ij}}^{\mathrm{n}}-\mathrm{F}_{\text {ideal, } \mathrm{j}}^{\mathrm{n}}\right)^{2}} \\
\mathrm{~d}_{\text {non-ideal }}=\sqrt{\sum_{\mathrm{j}=1}^{\mathrm{n}}\left(\mathrm{F}_{\mathrm{ij}}^{\mathrm{n}}-\mathrm{F}_{\text {non-ideal } \mathrm{j}}^{\mathrm{n}}\right)^{2}}
\end{gathered}
$$

In the TOPSIS approach, a $C l_{j}$ parameter is described, as indicated in Equation (13), and its minimum value is desirable and selected as the best final solution (Ahmadi et al., 2016).

$$
\mathrm{cl}_{\mathrm{j}}=\frac{\mathrm{d}_{\text {non-ideal }}}{\mathrm{d}_{\text {ideal }}+\mathrm{d}_{\text {non-ideal }}}
$$

\section{Results and discussion}

\subsection{Development of regression models}

Table 1 presents the range and levels of design variables and coded values. Three different types of regression models, e.g. linear, two-factor interaction, and quadratic, have been developed. The coefficient of determination, $\mathrm{R}^{2}$, is calculated to compare the performance of each model and to select the most appropriate type of model. The excellent fit between the 
measured and predicted values would have $\mathrm{R}^{2}=1$. The calculated results for these three types of models are listed in Table 2. The accuracy of quadratic models has been evidenced for the $\mathrm{P}_{\text {comp }}, \mathrm{Q}_{\text {evap }}, \mathrm{COP}, \mathrm{T}_{\text {dis }}$, and $\mathrm{m}_{\text {ref }}$ under the given experimental conditions by high $\mathrm{R}^{2}$ values. The selection of this type of model also allows one to quantify the curvature effects and to comprehensively investigate the effects and interactions of design variables on the responses. Therefore, quadratic models are selected for further analysis. The analysis of variance (ANOVA) is carried out to achieve the contribution and interaction between the design variables and the corresponding responses. The probability, p-value, is calculated for the quadratic type of model to judge its significance. The p-value of less than 0.05 indicates insignificant lack of fit. The ANOVA results for the relevant responses have been summarized in Table 3. The response variable related to the quadratic model is presented in Table 4. The $\mathrm{P}_{\text {comp }}, \mathrm{Q}_{\text {evap }}, \mathrm{COP}, \mathrm{T}_{\mathrm{dis}}$, and $\mathrm{m}_{\text {ref }}$ are modeled as the sum of a constant, four first-order effects ( $\mathrm{T}_{\text {evap }}, \mathrm{T}_{\mathrm{c}}, \mathrm{SHD}$, and SCD), six interactive effects ( $\mathrm{T}_{\text {evap }}$ and $\mathrm{T}_{\mathrm{c}}, \mathrm{T}_{\text {evap }}$ and $\mathrm{SHD}, \mathrm{T}_{\text {evap }}$ and $\mathrm{SCD}$, $\mathrm{T}_{\mathrm{c}}$ and SHD, $\mathrm{T}_{\mathrm{c}}$ and $\mathrm{SCD}$, and SHD and $\left.\mathrm{SCD}\right)$, and four second-order effects $\left(\mathrm{T}_{\mathrm{evap}}{ }^{2}, \mathrm{~T}_{\mathrm{c}}{ }^{2}, \mathrm{SHD}^{2}\right.$, and $\left.\mathrm{SCD}^{2}\right)$.

Table 1. Range and levels of independent variables for the CCD used in this study.

\begin{tabular}{cccccccc}
\hline \multirow{2}{*}{$\begin{array}{c}\text { Design } \\
\text { variable }\end{array}$} & \multirow{2}{*}{ Label } & \multirow{2}{*}{ Unit } & \multicolumn{5}{c}{ Levels } \\
\cline { 4 - 8 } & & & $-\boldsymbol{\alpha}$ & $\mathbf{- 1}$ & $\mathbf{0}$ & $+\mathbf{1}$ & $+\boldsymbol{\alpha}$ \\
\hline $\mathrm{T}_{\text {evap }}$ & $\mathrm{A}$ & ${ }^{\circ} \mathrm{C}$ & -28.87 & -14.99 & -1.12 & 12.76 & 26.64 \\
$\mathrm{~T}_{\mathrm{c}}$ & $\mathrm{B}$ & ${ }^{\circ} \mathrm{C}$ & 34.91 & 24.5 & 29.71 & 34.91 & 40.12 \\
$\mathrm{SHD}$ & $\mathrm{C}$ & $\mathrm{K}$ & 13.36 & 10.49 & 11.93 & 13.36 & 14.80 \\
$\mathrm{SCD}$ & $\mathrm{D}$ & $\mathrm{K}$ & 15.66 & 8.25 & 11.96 & 15.66 & 19.37 \\
\hline
\end{tabular}

Table 2. Accuracy comparison of the linear, two-factor interaction, and quadratic models for estimating $P_{\text {comp, }}$ $Q_{\text {evap }}, C O P, T_{\text {dis }}$, and $m_{\text {ref. }}$

\begin{tabular}{cccccccccc}
\hline Parameter & \multicolumn{3}{c}{ Linear } & \multicolumn{4}{c}{ Two-factor interaction } & \multicolumn{3}{c}{ Quadratic } \\
\cline { 2 - 10 } & $\begin{array}{c}\text { R- } \\
\text { Squared }\end{array}$ & $\begin{array}{c}\text { Adj R- } \\
\text { Squared }\end{array}$ & $\begin{array}{c}\text { Adeq } \\
\text { Precision }\end{array}$ & $\begin{array}{c}\text { R- } \\
\text { Squared }\end{array}$ & $\begin{array}{c}\text { Adj R- } \\
\text { Squared }\end{array}$ & $\begin{array}{c}\text { Adeq } \\
\text { Precision }\end{array}$ & $\begin{array}{c}\text { R- } \\
\text { Squared }\end{array}$ & $\begin{array}{c}\text { Adj R- } \\
\text { Squared }\end{array}$ & $\begin{array}{c}\text { Adeq } \\
\text { Precision }\end{array}$ \\
\hline $\mathrm{P}_{\text {comp }}$ & 0.9244 & 0.9147 & 25.302 & 0.9437 & 0.9212 & 19.986 & 0.9736 & 0.9560 & 24.614 \\
Qevap $_{\text {ex }}$ & 0.9888 & 0.9874 & 77.080 & 0.9923 & 0.9892 & 57.843 & 0.9994 & 0.9990 & 162.466 \\
COP & 0.9801 & 0.9776 & 60.816 & 0.9873 & 0.9822 & 48.633 & 0.9989 & 0.9982 & 128.410 \\
$\mathrm{~T}_{\text {dis }}$ & 0.9653 & 0.9608 & 50.652 & 0.9767 & 0.9674 & 38.778 & 0.9932 & 0.9887 & 57.758 \\
$\mathrm{~m}_{\text {ref }}$ & 0.9911 & 0.9899 & 85.321 & 0.9944 & 0.9922 & 65.742 & 0.9993 & 0.9988 & 144.964 \\
\hline
\end{tabular}

Table 3. Result of ANOVA analysis for quadratic model. 


\begin{tabular}{|c|c|c|c|c|c|c|c|c|c|c|}
\hline \multirow[b]{2}{*}{ Source } & \multicolumn{2}{|c|}{ P comp $_{\text {c }}$} & \multicolumn{2}{|c|}{$Q_{\text {evap }}$} & \multicolumn{2}{|c|}{ COP } & \multicolumn{2}{|c|}{$\mathbf{T}_{\text {dis }}$} & \multicolumn{2}{|c|}{$\mathbf{m}_{\text {ref }}$} \\
\hline & $\begin{array}{c}\text { Sum of } \\
\text { Squares }\end{array}$ & $\begin{array}{l}\text { p-value } \\
\text { Prob > F }\end{array}$ & $\begin{array}{l}\text { Sum of } \\
\text { Squares }\end{array}$ & $\begin{array}{c}\text { p-value } \\
\text { Prob > F }\end{array}$ & $\begin{array}{c}\text { Sum of } \\
\text { Squares }\end{array}$ & $\begin{array}{c}\text { p-value } \\
\text { Prob }>\text { F }\end{array}$ & $\begin{array}{c}\text { Sum of } \\
\text { Squares }\end{array}$ & $\begin{array}{c}\text { p-value } \\
\text { Prob }> \\
\text { F }\end{array}$ & $\begin{array}{c}\text { Sum of } \\
\text { Squares }\end{array}$ & $\begin{array}{l}\text { p-value } \\
\text { Prob }>\text { F }\end{array}$ \\
\hline Model & 16655.47 & $<0.0001$ & $1.071 \mathrm{E}+07$ & $<0.0001$ & 73.18 & $<0.0001$ & 1893.15 & $<0.0001$ & 282.73 & $<0.0001$ \\
\hline A & 0.88 & 0.8418 & $1.271 \mathrm{E}+06$ & $<0.0001$ & 8.08 & $<0.0001$ & 160.71 & $<0.0001$ & 34.62 & $<0.0001$ \\
\hline B & 945.52 & $<0.0001$ & 5883.44 & 0.0002 & 0.19 & $<0.0001$ & 30.99 & $<0.0001$ & 0.010 & 0.3099 \\
\hline $\mathrm{C}$ & 5.58 & 0.6156 & 8.40 & 0.8691 & $5.126 \mathrm{E}-04$ & 0.7189 & 1.30 & 0.1606 & $1.279 \mathrm{E}-03$ & 0.7171 \\
\hline $\mathrm{D}$ & 2.52 & 0.7352 & 447.93 & 0.2367 & $5.000 \mathrm{E}-05$ & 0.9104 & 0.22 & 0.5550 & $2.220 \mathrm{E}-04$ & 0.8799 \\
\hline $\mathrm{AB}$ & 19.07 & 0.3569 & 1664.33 & 0.0287 & 0.13 & $<0.0001$ & 0.91 & 0.2384 & 7.944E-03 & 0.3704 \\
\hline $\mathrm{AC}$ & 61.09 & 0.1065 & 11.46 & 0.8474 & $3.480 \mathrm{E}-03$ & 0.3526 & 0.29 & 0.4996 & $6.651 \mathrm{E}-03$ & 0.4118 \\
\hline $\mathrm{AD}$ & 8.25 & 0.5422 & 387.78 & 0.2698 & $5.183 \mathrm{E}-03$ & 0.2590 & 0.011 & 0.8927 & $3.034 \mathrm{E}-03$ & 0.5776 \\
\hline $\mathrm{BC}$ & 55.69 & 0.1223 & 225.43 & 0.3972 & $5.007 \mathrm{E}-03$ & 0.2670 & 1.62 & 0.1193 & $1.476 \mathrm{E}-03$ & 0.6971 \\
\hline $\mathrm{BD}$ & 15.65 & 0.4030 & 494.70 & 0.2144 & $2.143 \mathrm{E}-03$ & 0.4640 & 1.33 & 0.1567 & $5.397 \mathrm{E}-03$ & 0.4590 \\
\hline CD & 6.82 & 0.5790 & 194.31 & 0.4313 & 4.497E-05 & 0.9150 & 1.18 & 0.1808 & $3.828 \mathrm{E}-03$ & 0.5321 \\
\hline $\mathrm{A}^{2}$ & 434.45 & 0.0002 & 69374.13 & $<0.0001$ & 0.81 & $<0.0001$ & 25.02 & $<0.0001$ & 1.26 & $<0.0001$ \\
\hline $\mathrm{B}^{2}$ & 17.41 & 0.3782 & 128.88 & 0.5206 & $3.994 \mathrm{E}-03$ & 0.3201 & 0.82 & 0.2625 & $1.009 \mathrm{E}-04$ & 0.9188 \\
\hline $\mathrm{C}^{2}$ & 21.77 & 0.3256 & 26.50 & 0.7699 & $4.279 \mathrm{E}-03$ & 0.3038 & 0.30 & 0.4920 & $1.277 \mathrm{E}-04$ & 0.9087 \\
\hline $\mathrm{D}^{2}$ & 11.53 & 0.4720 & 0.72 & 0.9616 & $6.176 \mathrm{E}-04$ & 0.6929 & 0.015 & 0.8790 & $2.953 \mathrm{E}-04$ & 0.8616 \\
\hline
\end{tabular}

Table 4. Quadratic equations for $P_{\text {comp }}, Q_{\text {evap }}, C O P, T_{\text {dis }}$, and $m_{\text {ref. }}$

\begin{tabular}{|c|c|}
\hline $\begin{array}{c}\text { Response } \\
\text { variable }\end{array}$ & Quadratic correlation \\
\hline $\mathrm{P}_{\text {comp }}$ & $\begin{array}{l}\mathrm{P}_{\text {comp }}=-739.698+6.381 \times \mathrm{T}_{\text {evap }}+31.185 \times \mathrm{T}_{\mathrm{c}}+127.101 \times \mathrm{SHD}-27.697 \times \mathrm{SCD} \\
+0.045 \times \mathrm{T}_{\text {evap }} \times \mathrm{T}_{\mathrm{c}}-0.743 \times \mathrm{T}_{\text {evap }} \times \mathrm{SHD}+0.076 \times \mathrm{T}_{\text {evap }} \times \mathrm{SCD}-1.74 \times \mathrm{T}_{\mathrm{c}} \times \mathrm{SHD} \\
+0.406 \times \mathrm{T}_{\mathrm{c}} \times \mathrm{SCD}+2.201 \times \mathrm{SHD} \times \mathrm{SCD}-0.077 \times \mathrm{T}_{\text {evap }}^{2}-0.167 \times \mathrm{T}_{\mathrm{c}}^{2}-4.175 \times \mathrm{SHD}^{2} \\
-0.412 \times \mathrm{SCD}^{2}\end{array}$ \\
\hline$Q_{\text {evap }}$ & $\begin{array}{l}\mathrm{Q}_{\text {evap }}=1578.997+74.963 \times \mathrm{T}_{\text {evap }}-55.174 \times \mathrm{T}_{\mathrm{c}}-77.417 \times \mathrm{SHD}+215.307 \times \mathrm{SCD} \\
-0.424 \times \mathrm{T}_{\text {evap }} \times \mathrm{T}_{\mathrm{c}}-0.322 \times \mathrm{T}_{\text {evap }} \times \mathrm{SHD}+0.518 \times \mathrm{T}_{\text {evap }} \times \mathrm{SCD}+3.5 \times \mathrm{T}_{\mathrm{c}} \times \mathrm{SHD} \\
-2.285 \times \mathrm{T}_{\mathrm{c}} \times \mathrm{SCD}-11.749 \times \mathrm{SHD} \times \mathrm{SCD}+0.975 \times \mathrm{T}_{\text {evap }}^{2}+0.454 \times \mathrm{T}_{\mathrm{c}}^{2}+4.606 \times \mathrm{SHD}^{2} \\
+0.103 \times \mathrm{SCD}^{2}\end{array}$ \\
\hline $\mathrm{COP}$ & $\begin{array}{l}\mathrm{COP}=18.852+0.187 \times \mathrm{T}_{\text {evap }}-0.37 \times \mathrm{T}_{\mathrm{c}}-1.783 \times \mathrm{SHD}+0.278 \times \mathrm{SCD} \\
-3.746 \mathrm{E}-003 \times \mathrm{T}_{\text {evap }} \times \mathrm{T}_{\mathrm{c}}+5.61 \mathrm{E}-003 \times \mathrm{T}_{\text {evap }} \times \mathrm{SHD}+1.894 \mathrm{E}-003 \times \mathrm{T}_{\text {evap }} \times \mathrm{SCD} \\
+0.016 \times \mathrm{T}_{\mathrm{c}} \times \mathrm{SHD}-4.757 \mathrm{E}-003 \times \mathrm{T}_{\mathrm{c}} \times \mathrm{SCD}-5.652 \times \mathrm{SHD} \times \mathrm{SCD}+3.321 \times \mathrm{T}_{\text {evap }}^{2} \\
+2.526 \times \mathrm{T}_{\mathrm{c}}^{2}+0.059 \times \mathrm{SHD}^{2}-3.018 \times \mathrm{SCD}^{2}\end{array}$ \\
\hline $\mathrm{T}_{\mathrm{dis}}$ & $\begin{array}{l}\mathrm{T}_{\text {dis }}=-20.284+0.209 \times \mathrm{T}_{\text {evap }}+5.229 \times \mathrm{T}_{\mathrm{c}}+10.99 \times \mathrm{SHD}-14.289 \times \mathrm{SCD} \\
-0.01 \times \mathrm{T}_{\text {evap }} \times \mathrm{T}_{\mathrm{c}}-0.051 \times \mathrm{T}_{\text {evap }} \times \mathrm{SHD}+0.003 \times \mathrm{T}_{\text {evap }} \times \mathrm{SCD}-0.297 \times \mathrm{T}_{\mathrm{c}} \times \mathrm{SHD} \\
+0.118 \times \mathrm{T}_{\mathrm{c}} \times \mathrm{SCD}+0.916 \times \mathrm{SHD} \times \mathrm{SCD}+0.019 \times \mathrm{T}_{\text {evap }}^{2}-0.036 \times \mathrm{T}_{\mathrm{c}}^{2}-0.491 \times \mathrm{SHD}^{2} \\
-0.015 \times \mathrm{SCD}^{2}\end{array}$ \\
\hline $\mathrm{m}_{\mathrm{ref}}$ & $\begin{array}{l}\mathrm{m}_{\text {ref }}=3.872+0.438 \times \mathrm{T}_{\text {evap }}-0.059 \times \mathrm{T}_{\mathrm{c}}+0.062 \times \mathrm{SHD}+0.891 \times \mathrm{SCD} \\
-0.001 \times \mathrm{T}_{\text {evap }} \times \mathrm{T}_{\mathrm{c}}-0.008 \times \mathrm{T}_{\text {evap }} \times \mathrm{SHD}+0.001 \times \mathrm{T}_{\text {evap }} \times \mathrm{SCD}+0.009 \times \mathrm{T}_{\mathrm{c}} \times \mathrm{SHD} \\
-0.008 \times \mathrm{T}_{\mathrm{c}} \times \mathrm{SCD}-0.052 \times \mathrm{SHD} \times \mathrm{SCD}+0.004 \times \mathrm{T}_{\text {evap }}^{2}-0.0004 \times \mathrm{T}_{\mathrm{c}}^{2}-0.01 \times \mathrm{SHD}^{2} \\
-0.002 \times \mathrm{SCD}^{2}\end{array}$ \\
\hline
\end{tabular}


The provided two-dimensional plots in Figure 4 are based on the influences of the levels of the factors studied, and hence presents the values estimated using the quadratic model as a function of the measured data on the horizontal axis. Different colors represent the response value at each corresponding point. In the present case, red represents the highest value all the way down to blue, which represents the lowest value. ANOVA results for each parameter are analyzed, and the 2D contour plots of each parameter are given. There, the interaction effect of the two parameters is plotted while the other two parameters are fixed. These contour plots are helpful for determining the optimum operating parameters. The results obtained are presented in further detail in following different subsections.

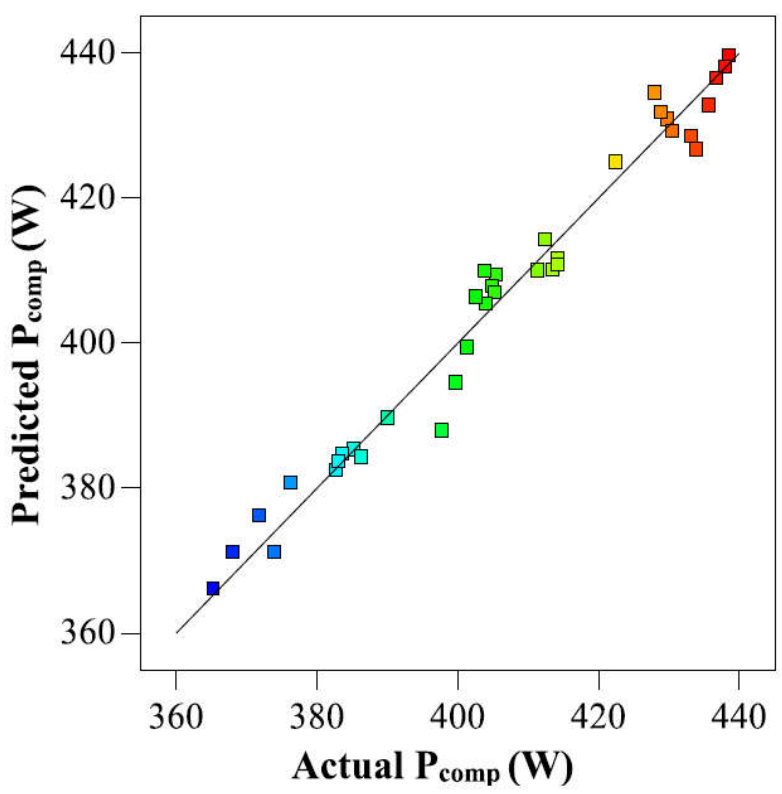

(a)

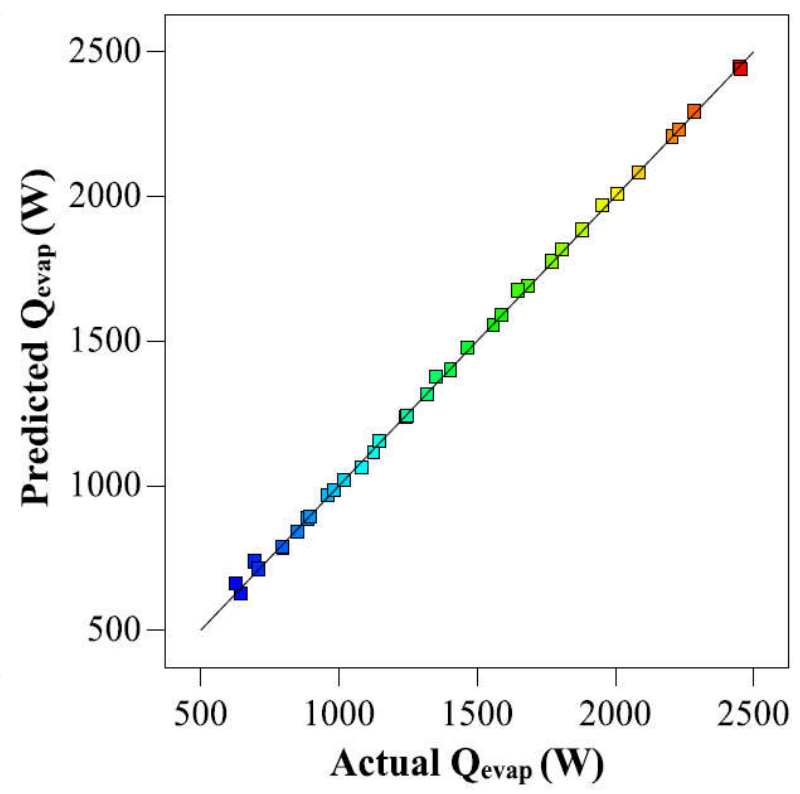

(b) 


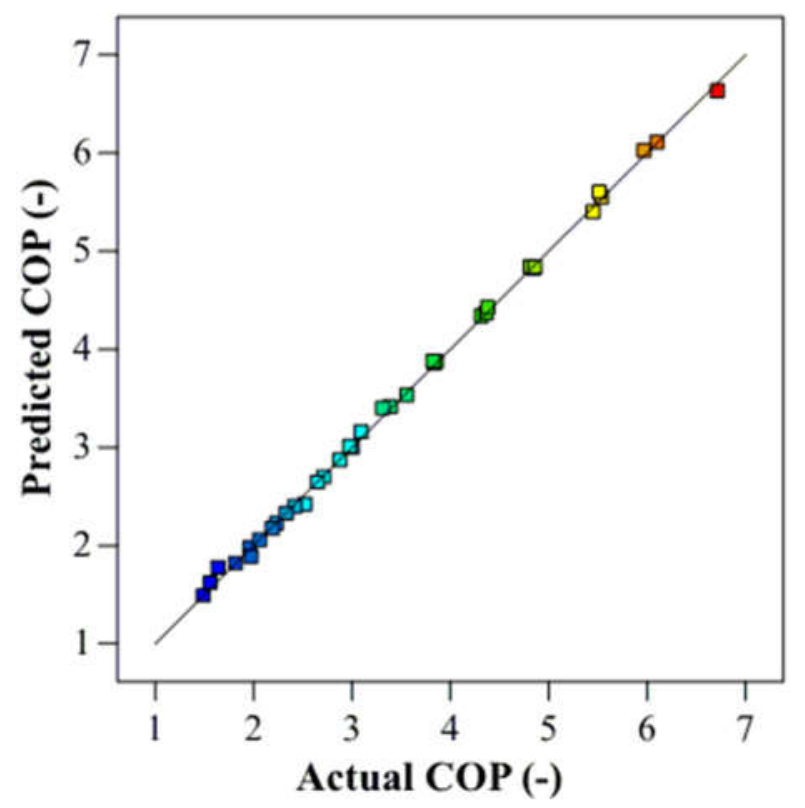

(c)

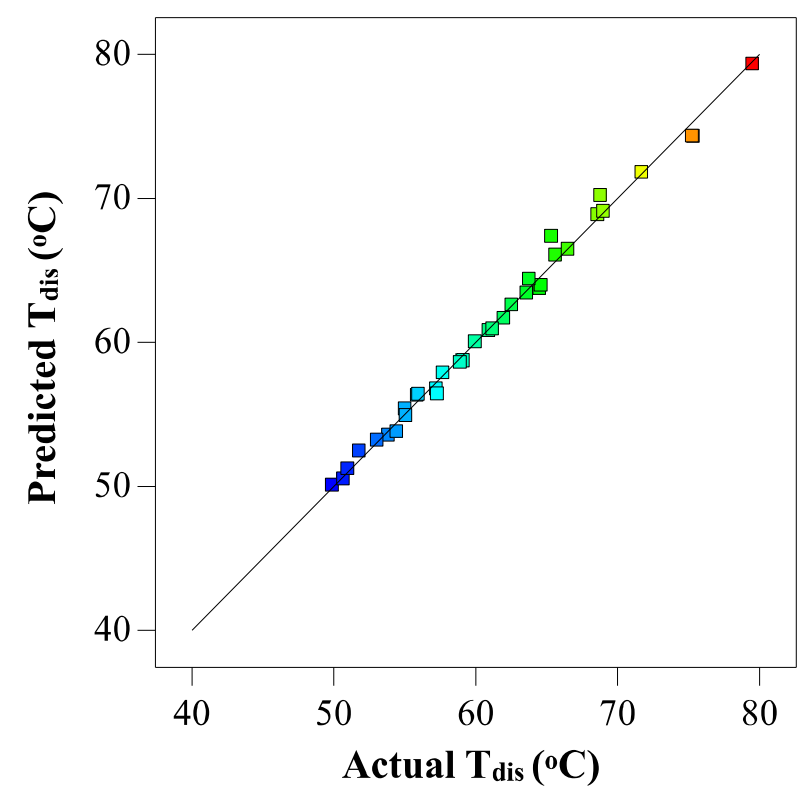

(d)

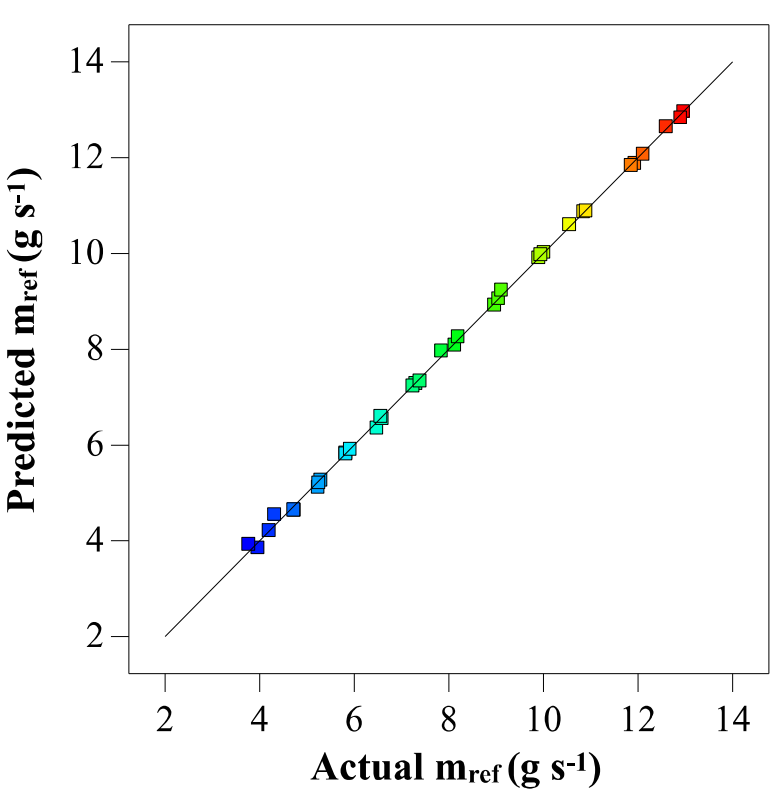

(e)

Figure 4. The relation between experimental and predicted values: (a) $P_{\text {comp; }}$ (b) $Q_{\text {evap; }}$; (c) COP; (d) $T_{\text {dis; }}$; (e) $m_{\text {ref. }}$

\subsubsection{Effect of factors on motor-compressor power consumption}

Figure 4(a) depicts values estimated using the developed motor-compressor power consumption predictive empirical model as a function of data measured along the horizontal axis. It is found that the values predicted by the model are in a good agreement with the 
corresponding experimental data. Value of the coefficient of determination is found to be close to unity, and the difference between the predicted $R^{2}$ and adjusted $R^{2}$ is not greater than 0.2 , thereby confirming the robustness of the developed model (Table 2). Based on the sum of squares, the linear term of $\mathrm{T}_{\mathrm{c}}$ with a contribution of $58.87 \%\left(0.05 \% \mathrm{~T}_{\mathrm{evap}}, 58.87 \% \mathrm{~T}_{\mathrm{c}}, 0.35 \%\right.$ SHD, and $0.16 \% \mathrm{SCD}$ ), the cross-interaction term of $\mathrm{T}_{\text {evap }} \times \mathrm{SHD}$ with a contribution of $3.80 \%$ $\left(1.19 \% \mathrm{~T}_{\text {evap }}\right.$ and $\mathrm{T}_{\mathrm{c}}, 3.80 \% \mathrm{~T}_{\text {evap }}$ and $\mathrm{SHD}, 0.51 \% \mathrm{~T}_{\text {evap }}$ and $\mathrm{SCD}, 3.47 \% \mathrm{~T}_{\mathrm{c}}$ and $\mathrm{SHD}, 0.97 \%$ $\mathrm{T}_{\mathrm{c}}$ and SCD, and $0.42 \% \mathrm{SHD}$ and $\mathrm{SCD}$ ), and the self-interaction term of $\mathrm{T}_{\text {evap }}{ }^{2}$ with a contribution of $27.05 \%\left(27.05 \% \mathrm{~T}_{\text {evap }}^{2}, 1.08 \% \mathrm{~T}_{\mathrm{c}}^{2}, 1.36 \% \mathrm{SHD}^{2}\right.$, and $\left.0.72 \% \mathrm{SCD}^{2}\right)$ have indicated the highest level of significance on the response (Table 3).

The 2D contour plots of the motor-compressor electrical power consumption are given in Figure 5. Overall, the results suggest that a higher value of middle evaporator temperature and lower value of middle condenser temperature lead to lower motor-compressor electrical power consumption. This effect can be explained by the reduction of the compression pressure ratio and hence, lower work of compression and isentropic efficiencies in a greater magnitude than the reduction of refrigerant mass flow rate. Moreover, Figure 5(e) indicates that in the specific studied cases, the motor-compressor electrical power consumption increases with the increase of the subcooling degree indicating that the refrigerant charge is above the optimal value. This is also supported by Figure 5(f), which also indicates that the motor-compressor electrical power consumption is reduced by the increased superheating degree since reduces the refrigerant mass flow rate. 


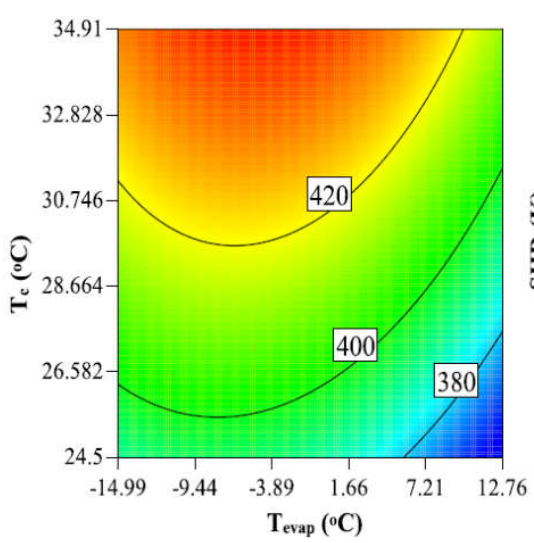

(a)

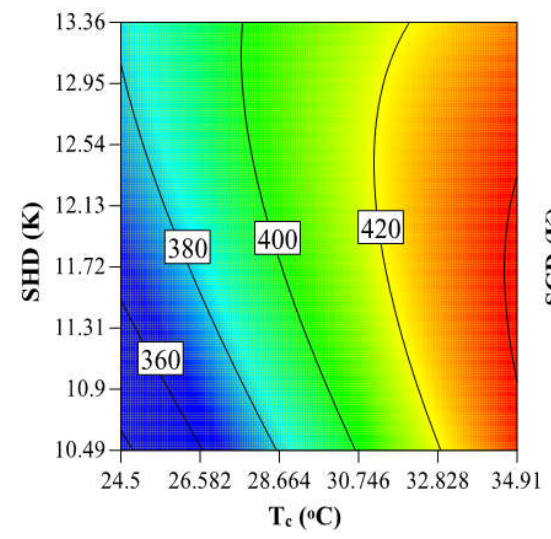

(d)

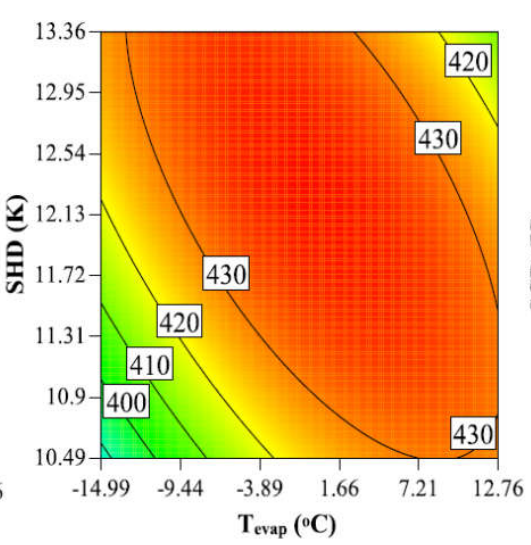

(b)

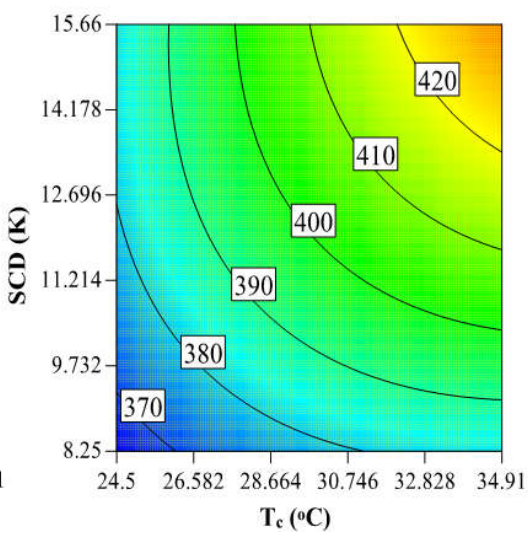

(e)

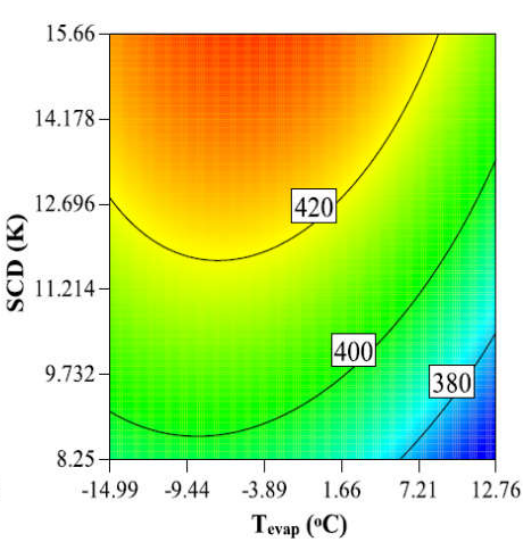

(c)

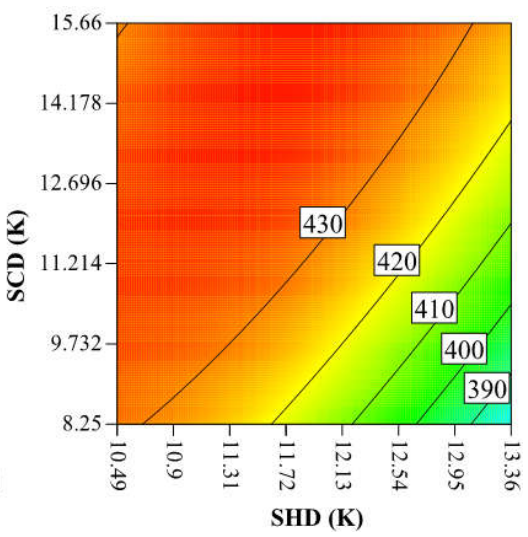

(f)

Figure 5. Contour plots of $P_{\text {comp }}$ in terms of: (a) $T_{\text {evap }} v s . T_{c}[S H D=13.36 \mathrm{~K}$ and $S C D=15.66 \mathrm{~K}]$; (b) $T_{\text {evap }} v s$. $S H D\left[T_{c}=34{ }^{\circ} \mathrm{C}\right.$ and $\left.S C D=15.66 \mathrm{~K}\right]$; (c) $T_{\text {evap }}$ vs. $S C D\left[T_{c}=34{ }^{\circ} \mathrm{C}\right.$ and $\left.S H D=13.36 \mathrm{~K}\right]$; (d) $T_{c}$ vs. SHD $\left[T_{\text {evap }}=5^{\circ} \mathrm{C}\right.$ and $\left.S C D=15.66 \mathrm{~K}\right]$; (e) $T_{c}$ vs. $S C D\left[T_{\text {evap }}=5^{\circ} \mathrm{C}\right.$ and $\left.S H D=13.36 \mathrm{~K}\right]$; (f) $S H D$ vs. $S C D\left[T_{\text {evap }}=5^{\circ} \mathrm{C}\right.$ and $\left.T_{c}=34^{\circ} \mathrm{C}\right]$.

\subsubsection{Effect of factors on cooling capacity}

Figure 4(b) displays the regression plot between the predicted and the corresponding experimental data concerning the evaluation of $\mathrm{Q}_{\text {evap. }}$. It is clear from the addressed plot that there is an excellent fit between the predicted and the actual values, thereby confirming the proposed model's great potential for use in practical applications. A large value of $\mathrm{R}^{2}$ and adjusted $R^{2}\left(R^{2}=0.9994\right.$ and adj- $\left.R^{2}=0.9990\right)$ show that the developed model for the application of interest is reliable and statistically accurate. To validate the obtained regression function mathematically, the ANOVA test is carried out and the results are provided in Table 3 . The results can be analyzed by the p-value from Table 3 , which is less than 0.0001 . Generally, the 
value implies that the model is significant and sufficient to be used. There is the possibility of removing the non-significant terms to simplify the model and increase the accuracy. Nevertheless, the purpose of this study is to investigate the influence of all operating parameters on the response variable. According to the sum of squares, the most significant linear term for $\mathrm{Q}_{\text {evap }}$ is found to be $\mathrm{T}_{\text {evap }}$ with a contribution of $94.16 \%\left(94.16 \% \mathrm{~T}_{\text {evap }}, 0.44 \% \mathrm{~T}_{\mathrm{c}}, 6.22 \mathrm{E}-04 \%\right.$ SHD, and $0.03 \% \mathrm{SCD}$ ). In addition, the cross-interaction term of $\mathrm{T}_{\mathrm{evap}} \times \mathrm{T}_{\mathrm{c}}$ with a contribution of $0.12 \%\left(0.12 \% \mathrm{~T}_{\text {evap }}\right.$ and $\mathrm{T}_{\mathrm{c}}, 8.49 \mathrm{E}-04 \% \mathrm{~T}_{\text {evap }}$ and $\mathrm{SHD}, 0.03 \% \mathrm{~T}_{\text {evap }}$ and $\mathrm{SCD}, 0.02 \% \mathrm{~T}_{\mathrm{c}}$ and SHD, $0.04 \% \mathrm{~T}_{\mathrm{c}}$ and SCD, and $0.01 \% \mathrm{SHD}$ and $\mathrm{SCD}$ ) and the self-interaction term of $\mathrm{T}_{\text {evap }}{ }^{2}$ with a contribution of $5.14 \%\left(5.14 \% \mathrm{~T}_{\text {evap }}^{2}, 0.01 \% \mathrm{~T}_{\mathrm{c}}^{2}, 1.19 \mathrm{E}-03 \% \mathrm{SHD}^{2}\right.$, and $5.33 \mathrm{E}-05 \%$ $\mathrm{SCD}^{2}$ ) are identified as parameters most significantly affecting the response variable. The results indicate that the most significant linear term model and cross-interaction model term on $\mathrm{P}_{\text {comp }}$ and $\mathrm{Q}_{\text {evap }}$ are different. Also, the important finding is that even if $\mathrm{T}_{\text {evap }}{ }^{2}$ is found to be statistically the most significant self-interaction term on both $\mathrm{P}_{\text {comp }}$ and $\mathrm{Q}_{\text {evap}}$, its contribution is different (Table 3).

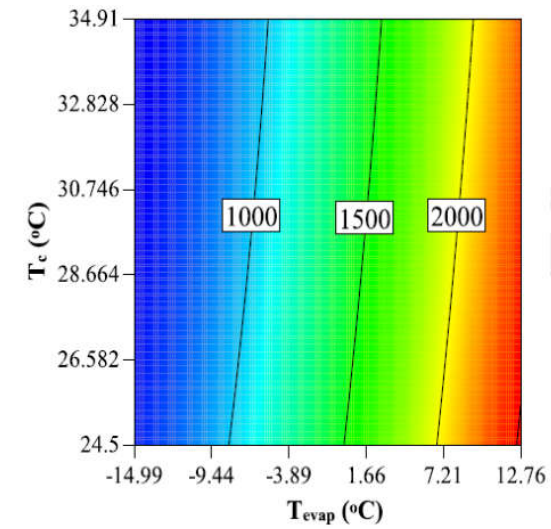

(a)

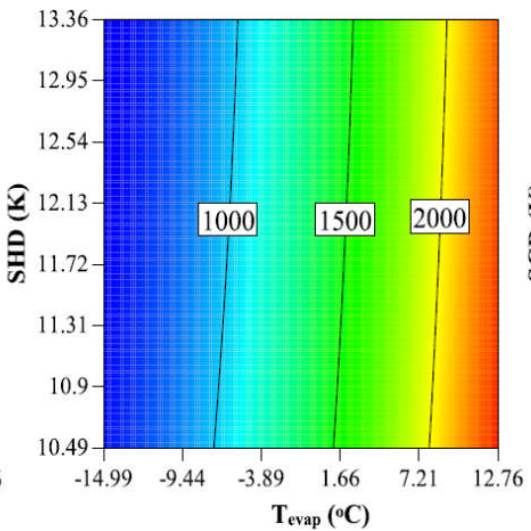

(b)

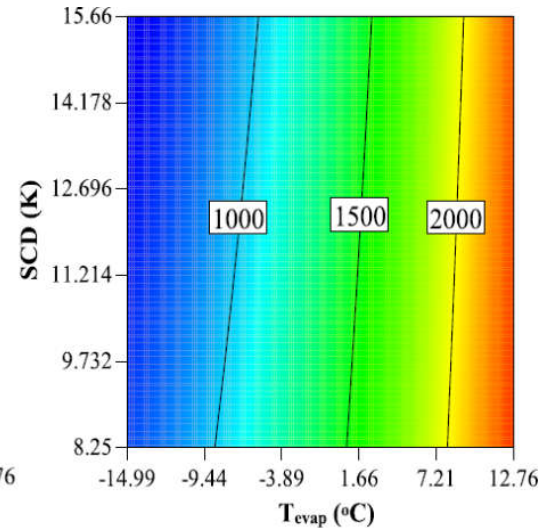

(c) 


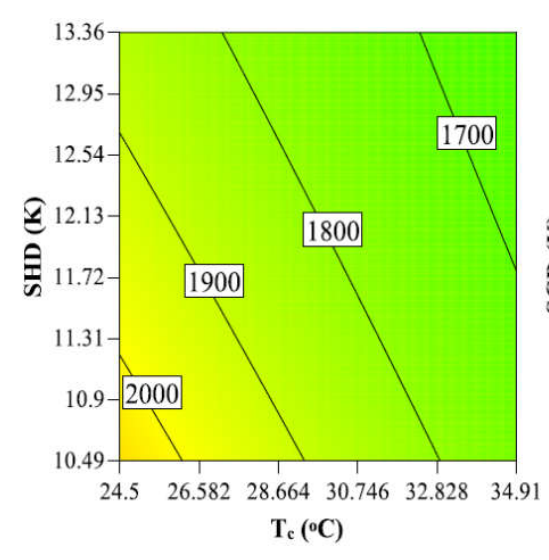

(d)

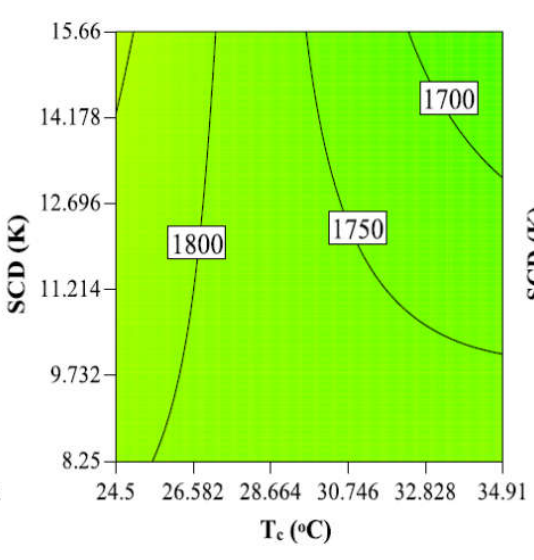

(e)

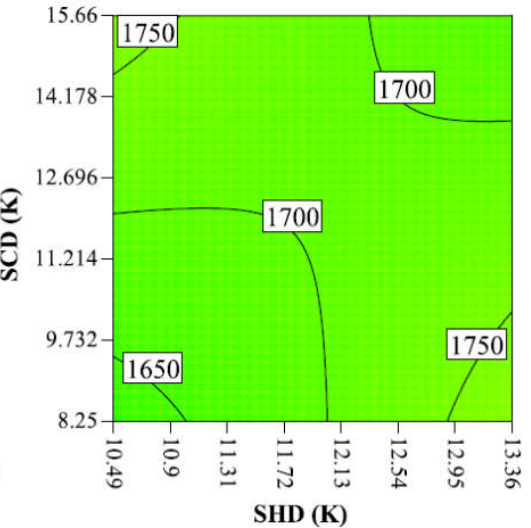

(f)

Figure 6. Contour plots of $Q_{\text {evap }}$ in terms of: (a) $T_{\text {evap }} v s . T_{c}[S H D=13.36 \mathrm{~K}$ and $S C D=15.66 \mathrm{~K}]$; (b) $T_{\text {evap }} v s$. $S H D\left[T_{c}=34{ }^{\circ} \mathrm{C}\right.$ and $\left.S C D=15.66 \mathrm{~K}\right]$; (c) $T_{\text {evap }}$ vs. $S C D\left[T_{c}=34^{\circ} \mathrm{C}\right.$ and $\left.S H D=13.36 \mathrm{~K}\right]$; (d) $T_{c}$ vs. SHD $\left[T_{\text {evap }}=5^{\circ} \mathrm{C}\right.$ and $\left.S C D=15.66 \mathrm{~K}\right]$; (e) $T_{c}$ vs. $S C D\left[T_{\text {evap }}=5^{\circ} \mathrm{C}\right.$ and $\left.S H D=13.36 \mathrm{~K}\right]$; (f) $S H D$ vs. $S C D\left[T_{\text {evap }}=5^{\circ} \mathrm{C}\right.$ and $\left.T_{c}=34^{\circ} \mathrm{C}\right]$.

Figure 6 indicates 2D contour plots of the cooling capacity, presenting the interaction effects based on a quadratic model. The contour areas in Figure 6(a-c) show that the middle evaporator temperature affects significantly more than the rest of parameters and cause an increase in cooling capacity because it augments the mass flow rate, and the compressor volumetric efficiency. Furthermore, the refrigerating degree is slighlty increased, but the condensing temperature has more influence on this parameter. At the highest subcooling degree and the middle evaporator temperature equal to $5{ }^{\circ} \mathrm{C}$, a decrease in the middle condenser temperature results in a gradual increase in cooling capacity (Figure 6(d)) because of the lower specific enthalpy at the inlet of the evaporator and lower compression rate. Also, as can be seen in Figure 6(f), at a middle evaporator temperature of $5{ }^{\circ} \mathrm{C}$ and a middle condenser temperature of $34^{\circ} \mathrm{C}$, an increase in the superheating degree and subcooling degree after a specific value leads to a decrease in the output. Overall, the results indicate that there are optimum operating conditions for higher cooling capacity requiring due consideration of interaction effects. This information can be used for the design and optimization of liquid-to-suction heat exchangers in this type of installation. 


\subsubsection{Effect of factors on COP}

To ensure the developed model adequately represents the actual data, the estimated RSM-generated model versus actual value plot is shown in Figure 4(c). It is observed from the comparison that the data are normally distributed around diagonal line, indicating good fitness with a low dispersion. The high $\mathrm{R}^{2}$ and adj- $\mathrm{R}^{2}$ values $\left(\mathrm{R}^{2}=0.9989\right.$ and $\left.\operatorname{Adj}-\mathrm{R}^{2}=0.9982\right)$ corresponding to the response variable COP demonstrate satisfactory prediction of the model. The ANOVA results of the proposed quadratic model for COP are presented in Table 3. Results obtained demonstrate greater dominance of the linear term of $\mathrm{T}_{\text {evap }}$ with a contribution of $87.49 \%\left(87.49 \% \mathrm{~T}_{\text {evap }}, 2.06 \% \mathrm{~T}_{\mathrm{c}}, 0.01 \% \mathrm{SHD}\right.$, and $\left.5.41 \mathrm{E}-04 \% \mathrm{SCD}\right)$, the cross-interaction term of $\mathrm{T}_{\text {evap }} \times \mathrm{T}_{\mathrm{c}}$ with a contribution of $1.41 \%\left(1.41 \% \mathrm{~T}_{\text {evap }}\right.$ and $\mathrm{T}_{\mathrm{c}}, 0.04 \% \mathrm{~T}_{\text {evap }}$ and $\mathrm{SHD}$, $0.06 \% \mathrm{~T}_{\text {evap }}$ and $\mathrm{SCD}, 0.05 \% \mathrm{~T}_{\mathrm{c}}$ and $\mathrm{SHD}, 0.02 \% \mathrm{~T}_{\mathrm{c}}$ and $\mathrm{SCD}$, and $4.87 \mathrm{E}-4 \% \mathrm{SHD}$ and $\left.\mathrm{SCD}\right)$, and the self-interaction term of $\mathrm{T}_{\text {evap }}{ }^{2}$ with a contribution of $8.77 \%\left(8.77 \% \mathrm{~T}_{\text {evap }}{ }^{2}, 0.04 \% \mathrm{~T}_{\mathrm{c}}{ }^{2}\right.$, $0.05 \% \mathrm{SHD}^{2}$, and $0.01 \% \mathrm{SCD}^{2}$ ) compared to other variables in terms of their influence on COP.

Figure $7(a-f)$ shows $2 \mathrm{D}$ contour plots of COP, indicating the interaction effects in a quadratic model equation. While SHD and SCD are assumed to be constant, Figure 7(a) shows COP reaches its maximum at maximum middle evaporator temperature and minimum middle condenser temperature (at the lowest compression ratio). However, determination of the optimum parametric conditions for higher COP requires considering the interaction effects of SHD and SCD with other two parameters. As COP depends on cooling capacity and power consumption, the discussion included in these sections could be used to explain the effect on COP. 


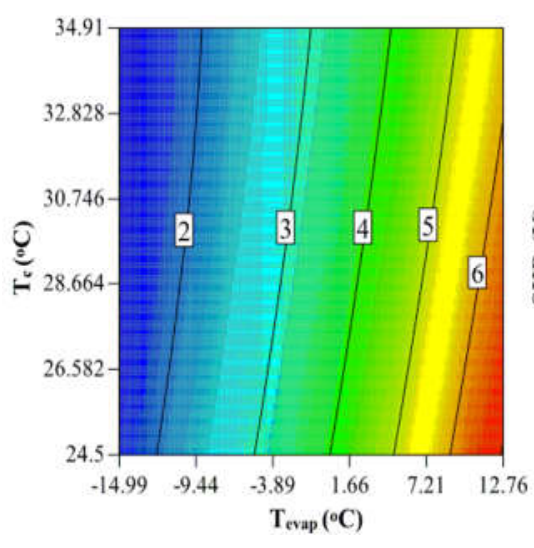

(a)

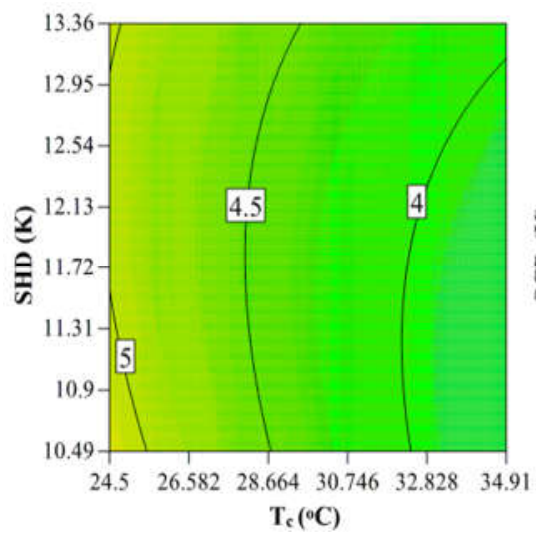

(d)

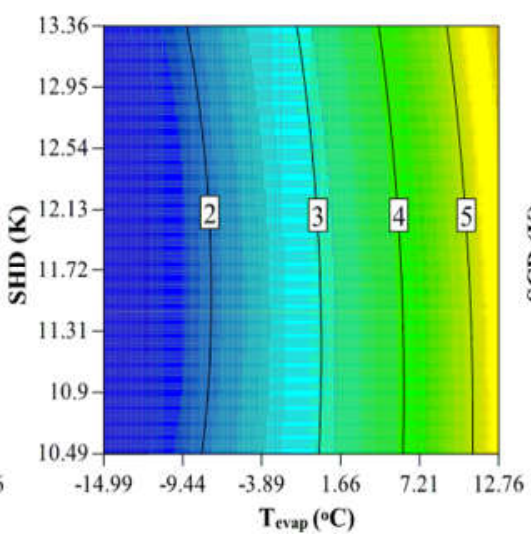

(b)

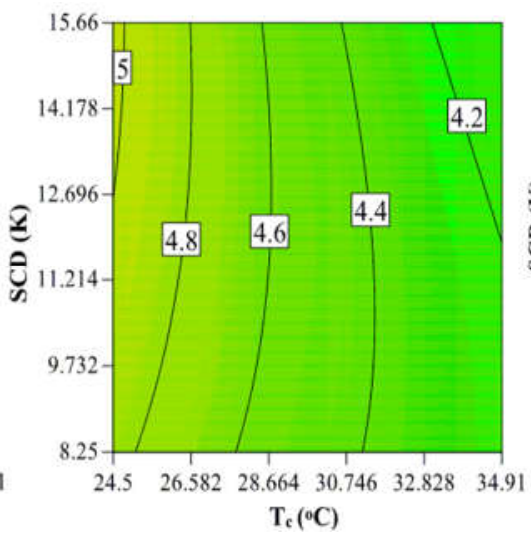

(e)

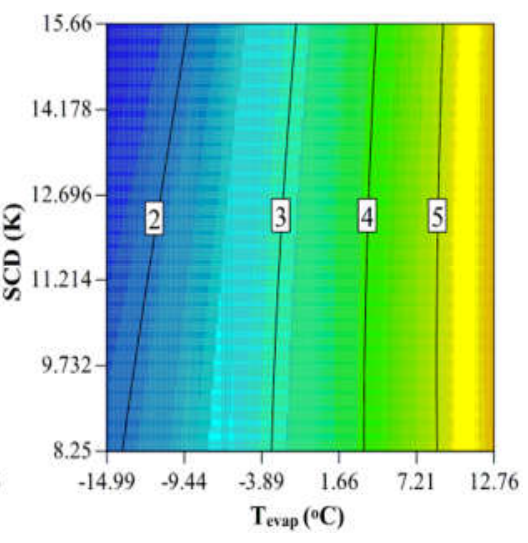

(c)

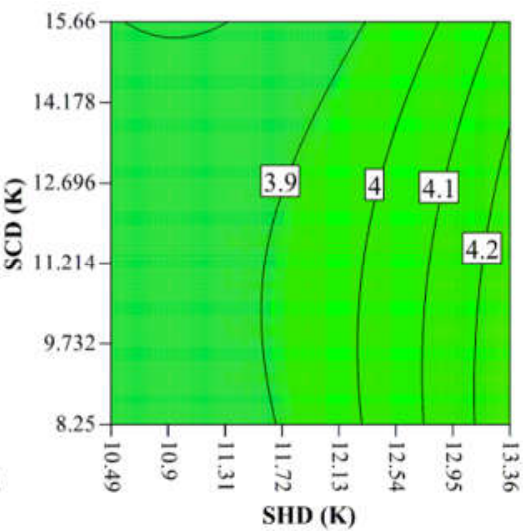

(f)

Figure 7. Contour plots of $Q_{\text {evap }}$ in terms of: (a) $T_{\text {evap }} v s . T_{c}[S H D=13.36 \mathrm{~K}$ and $S C D=15.66 \mathrm{~K}]$; (b) $T_{\text {evap }} v s . S H D$ $\left[T_{c}=34^{\circ} \mathrm{C}\right.$ and $\left.S C D=15.66 \mathrm{~K}\right]$; (c) $T_{\text {evap }}$ vs. $S C D\left[T_{c}=34^{\circ} \mathrm{C}\right.$ and $\left.S H D=13.36 \mathrm{~K}\right]$; (d) $T_{c}$ vs. $S H D\left[T_{\text {evap }}=5{ }^{\circ} \mathrm{C}\right.$ and $S C D=15.66 \mathrm{~K}]$; (e) $T_{c}$ vs. $S C D\left[T_{\text {evap }}=5{ }^{\circ} \mathrm{C}\right.$ and $\left.S H D=13.36 \mathrm{~K}\right]$; (f) $S H D$ vs. $S C D\left[T_{\text {evap }}=5{ }^{\circ} \mathrm{C}\right.$ and $\left.T_{c}=34^{\circ} \mathrm{C}\right]$.

\subsubsection{Effect of factors on discharge temperature}

Figure 4(d) illustrates an appropriate correlation between predicted values against those experimentally obtained, thereby indicating the efficiency and favorable performance of the developed model because points are close to the $45^{\circ}$ line. The calculated related statistical error values for $T_{\text {dis }}$ is found to be $R^{2}=0.9932$ and adj $-R^{2}=0.9887$. This indicates that the developed model adequately fits the experimental data. In Table 3, ANOVA evaluation for the regression equation is presented. The small $p$-value $(p<0.05)$ confirms high significance of the model. According to the sum of squares, the most significant linear term for $T_{\text {dis }}$ is found to be $T_{\text {evap }}$ with a contribution of $71.52 \%\left(71.52 \% \mathrm{~T}_{\text {evap }}, 13.79 \% \mathrm{~T}_{\mathrm{c}}, 0.58 \% \mathrm{SHD}\right.$, and $\left.0.10 \% \mathrm{SCD}\right)$. This 
means that $T_{\text {dis }}$ significantly varies with changes in the values of $T_{\text {evap }}$. Moreover, the crossinteraction term of $\mathrm{T}_{\mathrm{c}} \times \mathrm{SHD}$ with a contribution of $0.72 \%\left(0.40 \% \mathrm{~T}_{\text {evap }}\right.$ and $\mathrm{T}_{\mathrm{c}}, 0.13 \% \mathrm{~T}_{\text {evap }}$ and SHD, 4.90E-03\% $\mathrm{T}_{\text {evap }}$ and SCD, $0.72 \% \mathrm{~T}_{\mathrm{c}}$ and $\mathrm{SHD}, 0.59 \% \mathrm{~T}_{\mathrm{c}}$ and $\mathrm{SCD}$, and $0.53 \% \mathrm{SHD}$ and $\mathrm{SCD})$ and the self-interaction term of $\mathrm{T}_{\text {evap }}{ }^{2}$ with a contribution of $11.13 \%\left(11.13 \% \mathrm{~T}_{\text {evap }}^{2}\right.$, $0.36 \% \mathrm{~T}_{\mathrm{c}}^{2}, 0.13 \% \mathrm{SHD}^{2}$, and $0.01 \% \mathrm{SCD}^{2}$ ) are identified for significantly affecting the response variable.

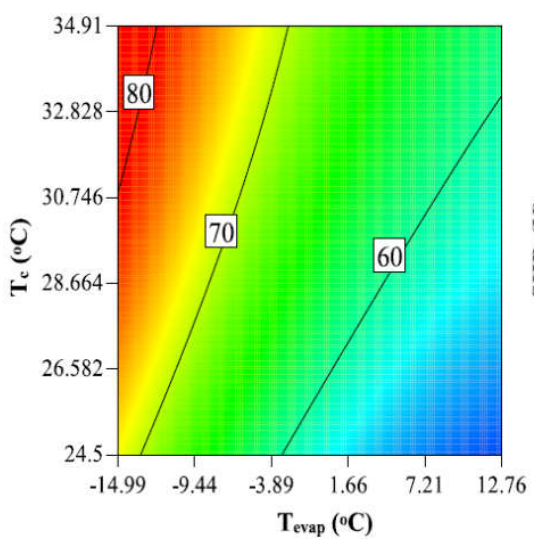

(a)

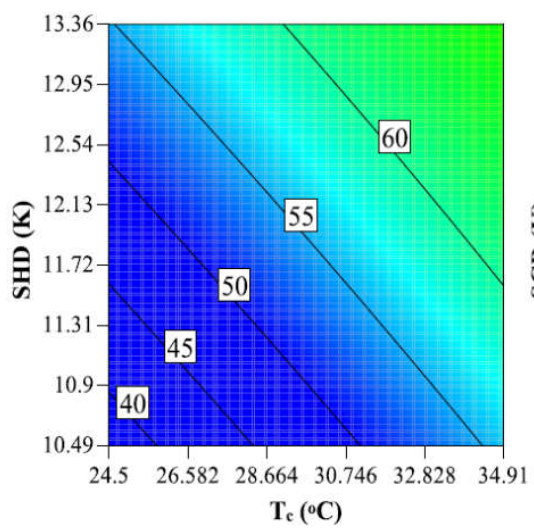

(d)

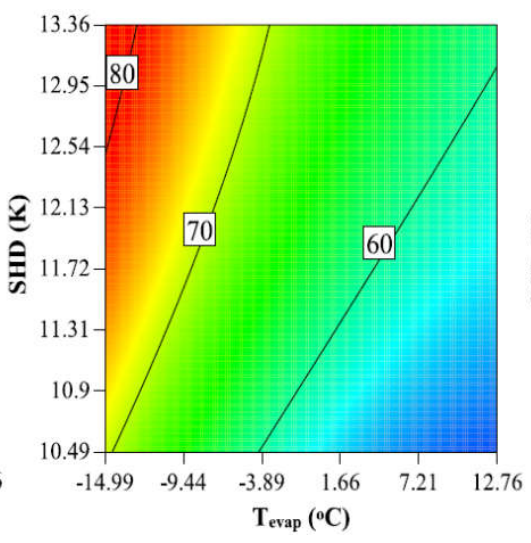

(b)

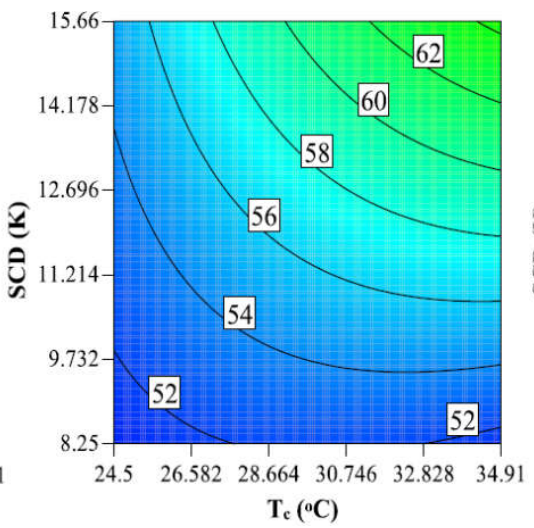

(e)

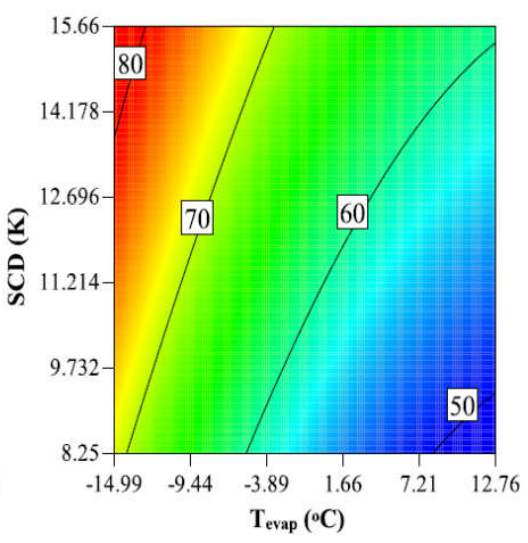

(c)

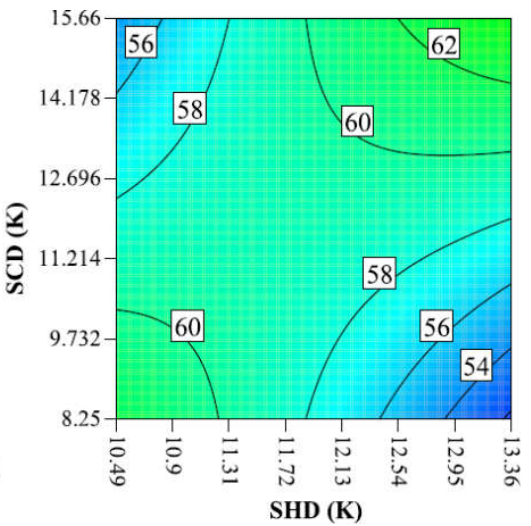

(f)

Figure 8. Contour plots of $T_{\text {dis }}$ in terms of: (a) $T_{\text {evap }} v s . T_{c}[S H D=13.36 \mathrm{~K}$ and $S C D=15.66 \mathrm{~K}]$; (b) $T_{\text {evap }} v s$. $S H D$ $\left[T_{c}=34{ }^{\circ} \mathrm{C}\right.$ and $\left.S C D=15.66 \mathrm{~K}\right]$; (c) $T_{\text {evap }}$ vs. $S C D\left[T_{c}=34{ }^{\circ} \mathrm{C}\right.$ and $\left.S H D=13.36 \mathrm{~K}\right]$; (d) $T_{c}$ vs. SHD $\left[T_{\text {evap }}=5{ }^{\circ} \mathrm{C}\right.$ and $S C D=15.66 \mathrm{~K}]$; (e) $T_{c}$ vs. $S C D\left[T_{\text {evap }}=5{ }^{\circ} \mathrm{C}\right.$ and $\left.S H D=13.36 \mathrm{~K}\right]$; (f) $S H D$ vs. $S C D\left[T_{\text {evap }}=5{ }^{\circ} \mathrm{C}\right.$ and $\left.T_{c}=34{ }^{\circ} \mathrm{C}\right]$.

The 2D contour plots of the discharge temperature are presented in Figure 8. Figure 8(a) shows that a combination of lower middle evaporator temperature and higher middle condenser temperature at constant superheating degree and subcooling degree results in the 
highest values of discharge temperature, since the compression ratio is increased and results in higher values of specific work of compression and a more irreversible compression at the end of this process. Figure $8(\mathrm{~b})$ illustrates that at the certain SCD and middle condensing temperature, the discharge temperature is greatly influenced by both SHD and middle evaporating temperature, so as for at fixed middle evaporation temperature the increase of SHD leads to the increase of the discharge temperature, since the discharge temperature reflects all the heat absorbed by the refrigerant, including the superheating process. Another observation is that the discharge temperature is lower at lower middle condenser temperature, considering $\left(\mathrm{T}_{\text {evap }}=5{ }^{\circ} \mathrm{C}\right.$ and $\left.\mathrm{SCD}=15.66 \mathrm{~K}\right)$ and $\left(\mathrm{T}_{\text {evap }}=5{ }^{\circ} \mathrm{C}\right.$ and $\left.\mathrm{SHD}=13.36 \mathrm{~K}\right)$ conditions, as is evident from the information in Figure 8(d) and Figure 8(e).

\subsubsection{Effect of factors on the mass flow rate}

Figure 4(e) illustrates the regression plot between the prediction results obtained by the quadratic equation and the actual values of $\mathrm{m}_{\text {ref }}$ with an excellent agreement for all data using the model. This is because almost all of the points fall considerably on the related straight line, thereby showing the accuracy of the model for estimating the output parameter. The calculated results concerning statistical performance criteria for the model are listed in Table 2. Based on a statistical investigation, the values of $\mathrm{R}^{2}$, adj- $\mathrm{R}^{2}$, and pred- $\mathrm{R}^{2}$ are close to unity. The achieved adequate precision is higher than 4 , and the pred- $\mathrm{R}^{2}$ is in reasonable agreement with the adj$\mathrm{R}^{2}$, i.e., the measured difference is less than 0.2 , thereby indicating the adopted model is significant. The ANOVA analysis results reported in Table 3 confirm that the obtained quadratic model is significant for this response. The linear, cross-interaction, and selfinteraction factors effects on $\mathrm{m}_{\text {ref }}$ are found to be $96.38 \% \mathrm{~T}_{\text {evap }}, 0.03 \% \mathrm{~T}_{\mathrm{c}}, 3.56 \mathrm{E}-03 \% \mathrm{SHD}$, 6.18E-04\% SCD, $0.02 \% \mathrm{~T}_{\text {evap }}$ and $\mathrm{T}_{\mathrm{c}}, 0.02 \% \mathrm{~T}_{\text {evap }}$ and $\mathrm{SHD}, 0.01 \% \mathrm{~T}_{\text {evap }}$ and $\mathrm{SCD}, 4.11 \mathrm{E}-03 \%$ $\mathrm{T}_{\mathrm{c}}$ and $\mathrm{SHD}, 0.02 \% \mathrm{~T}_{\mathrm{c}}$ and SCD, 0.01\% SHD and $\mathrm{SCD}, 3.51 \% \mathrm{~T}_{\text {evap }}{ }^{2}, 2.81 \mathrm{E}-04 \% \mathrm{~T}_{\mathrm{c}}{ }^{2}, 3.56 \mathrm{E}-$ 
$04 \% \mathrm{SHD}^{2}$, and $8.22 \mathrm{E}-04 \% \mathrm{SCD}^{2}$. Regarding $\mathrm{m}_{\text {ref, }}$, the highest contribution is observed from the linear term $\mathrm{T}_{\text {evap, }}$ with a contribution of $96.38 \%$, while the self-interaction factor $\mathrm{T}_{\mathrm{c}}{ }^{2}$ demonstrates the lowest contribution.

Similarly, as done for the other parameters, 2D contour plots of the refrigerant mass flow rate are presented in Figure 9. In general, the higher the middle evaporator temperature, the higher the refrigerant mass flow rate. In particular, the effect of middle evaporator temperature is dominant for the refrigerant mass flow value due to its effect on the compressor suction density together with the higher volumetric efficiency. This is illustrated in Figure 9(ac). The effect of the SHD on mass flow is seen from Figure 9(d) where it is evident that the mass flow rate decreases by increasing SHD in certain operating conditions where the suction density is more decreased. The middle condensing temperature has a slight effect on the refrigerant mass flow (Figure 9(a), Figure 9(d-e)) due to its slight influence on compressor volumetric efficiency through the increase of the compression ratio.

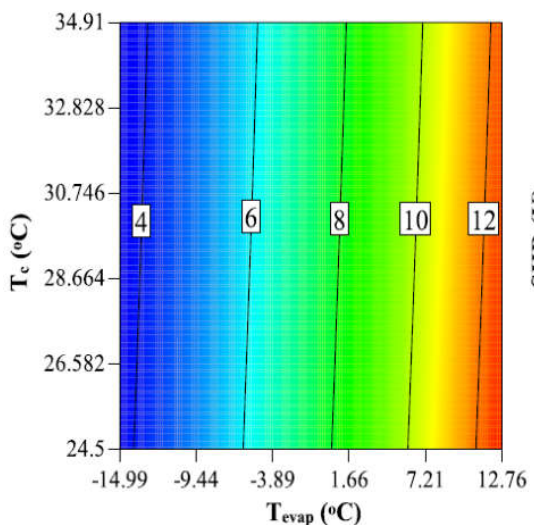

(a)

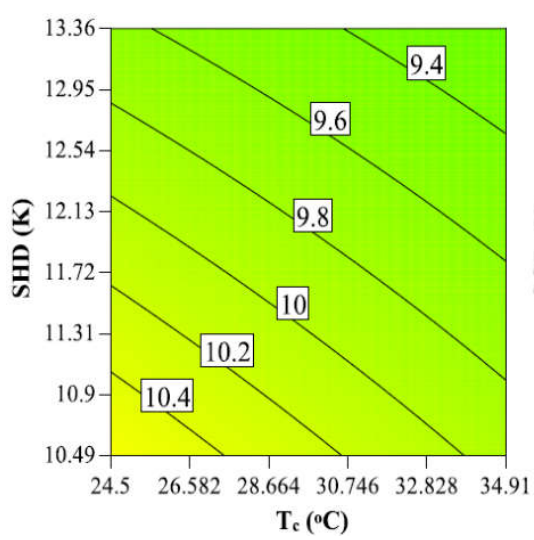

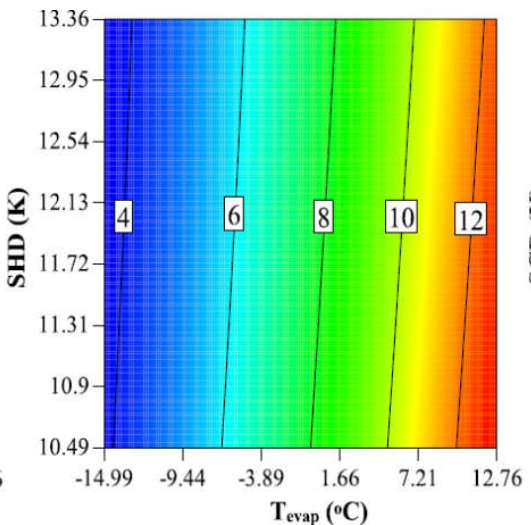

(b)

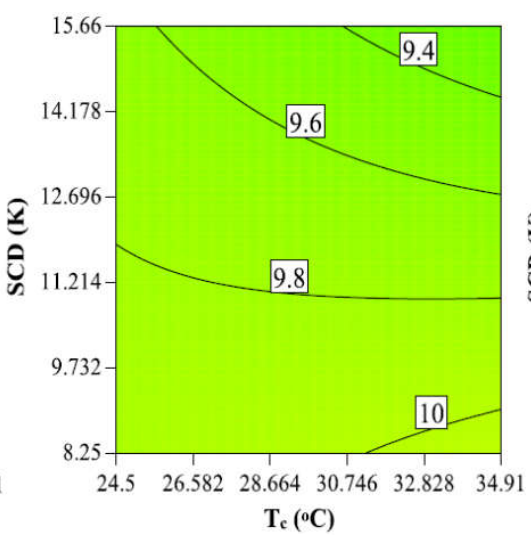

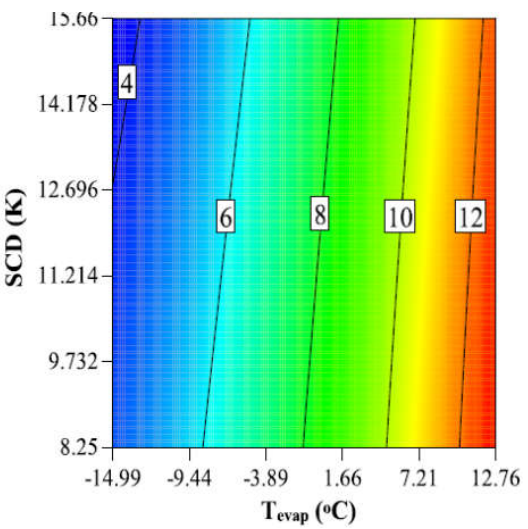

(c)

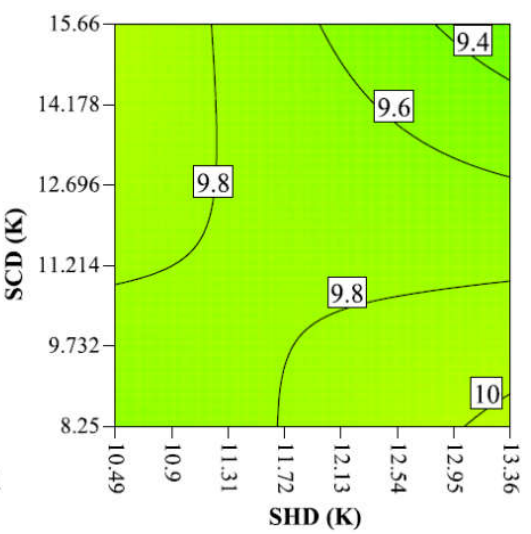


(d)

(e)

(f)

Figure 9. Contour plots of $m_{\text {ref }}$ in terms of: (a) $T_{\text {evap }}$ vs. $T_{c}[S H D=13.36 \mathrm{~K}$ and $S C D=15.66 \mathrm{~K}]$; (b) $T_{\text {evap }} v s . S H D$ $\left[T_{c}=34{ }^{\circ} \mathrm{C}\right.$ and $\left.S C D=15.66 \mathrm{~K}\right]$; (c) $T_{\text {evap }}$ vs. $S C D\left[T_{c}=34{ }^{\circ} \mathrm{C}\right.$ and $\left.S H D=13.36 \mathrm{~K}\right]$; (d) $T_{c}$ vs. $S H D\left[T_{\text {evap }}=5{ }^{\circ} \mathrm{C}\right.$ and $S C D=15.66 \mathrm{~K}]$; (e) $T_{c}$ vs. $S C D\left[T_{\text {evap }}=5{ }^{\circ} \mathrm{C}\right.$ and $\left.S H D=13.36 \mathrm{~K}\right]$; (f) $S H D$ vs. $S C D\left[T_{\text {evap }}=5{ }^{\circ} \mathrm{C}\right.$ and

$$
\left.T_{c}=34{ }^{\circ} \mathrm{C}\right] \text {. }
$$

\subsection{Optimization results}

In an R450A vapor compression refrigeration system, it is desired to minimize the discharge temperature and motor-compressor electrical power consumption, and maximize the refrigerant mass flow rate and cooling capacity. Consequently, the combination of these factors would lead to an improvement in COP. The comparison of these objective functions at different values of input parameters becomes more complicated when one wants to optimize three of them simultaneously. Accordingly, in this study, a multi-objective optimization is carried out to achieve the optimal conditions taking into account more than one target at the same time.

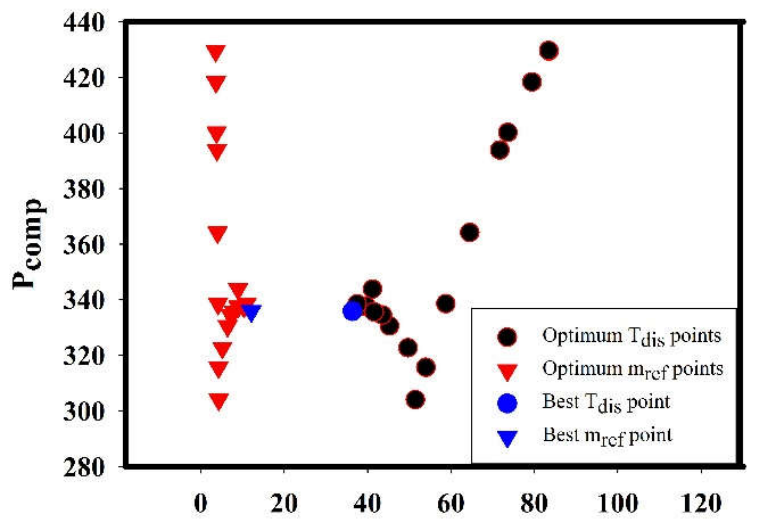

(a)

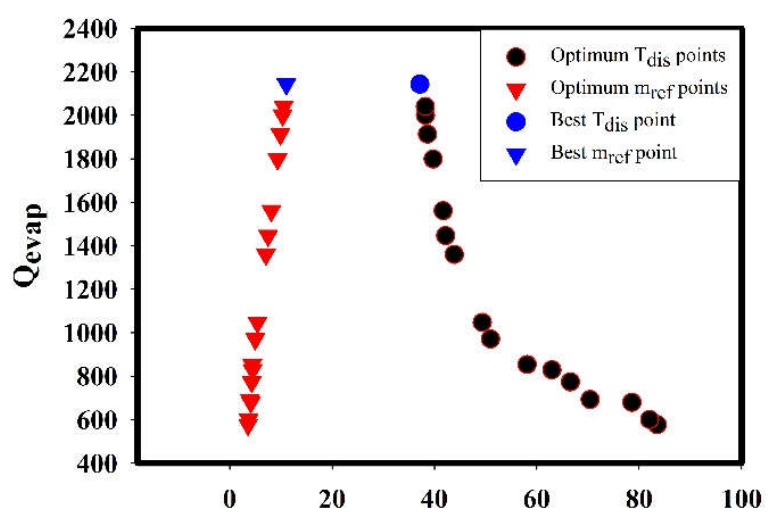

(b)

Figure 10. The Pareto front calculated using NSGA II: trade-off values for the objective functions for (a) first scenario; (b) second scenario.

Discussion in Section 3.1 indicates that the developed models can be used to predict outcomes based on the independent variables. Besides, the validation of the obtained models confirmed the non-existence of any statistically significant differences between results achieved by the experiment and those estimated by the introduced models. Therefore, the derived quadratic equations are implemented for two triple multi-objective optimizations. In 
this case, two scenarios are taken into consideration to investigate the simultaneous optimization of different sets of objective functions, and in each scenario, three objective functions are considered. After that, the NSGA II is used to determine the set of optimal conditions of $\mathrm{T}_{\text {evap, }}, \mathrm{T}_{\mathrm{c}}, \mathrm{SHD}$, and $\mathrm{SCD}$. Hence, in the optimization process, the limitations exposed in Equations (14) to (17) are considered.

$$
\begin{gathered}
-14.99 \leq \mathrm{T}_{\text {evap }} \leq 12.76 \\
24.5 \leq \mathrm{T}_{\mathrm{c}} \leq 34.91 \\
10.49 \leq \mathrm{SHD} \leq 13.39 \\
8.25 \leq \mathrm{SCD} \leq 15.66
\end{gathered}
$$

In the optimization simulations, the motor-compressor electrical power consumption, discharge temperature, and the refrigerant mass flow rate simultaneously are used as the objective functions for the first scenario, and the cooling capacity, refrigerant mass flow rate, and discharge temperature simultaneously are considered for the second scenario. The parameters used in the execution of NSGA II for the above problem are: population size of 50, a crossover probability of 0.8 , and a Pareto front population fraction of 0.35 . Furthermore, the selection function employed is 'tournament' with a size of 2 and 'intermediate' crossover function is selected.

The NSGA II method provides a wide population of non-dominated solutions called the Pareto front, which attempts to include all possible trade-offs between the defined objective functions. In this study, the NSGA II is run ten times for each case of optimization, and the first ranked Pareto fronts are selected. No considerable differences in the final optimum Pareto are detected. The information about the Pareto optimal solutions in both cases after convergence of NSGA II is graphically shown in Figure 10. Moreover, the achieved optimum numerical values of the objective functions and their corresponding optimum process variables for each optimum Pareto front shown in Figure 10 are summarized in Table 5. It is important 
to note that all the results are optimal conditions and non-dominated. As a result, each solution can be chosen as an incomparable solution, and the user based upon the predefined criteria may select a solution that best matches his/her needs and gives a better insight into the optimization. Putting it in another way, it is possible for designers to choose an optimum design through the reported results and the ultimate decision depends on the importance of each variable.

Nevertheless, TOPSIS decision maker is applied to the Pareto optimal solutions to select the best solution for each case scenario shown in Figure 10. The discharge temperature meets its minimum, $36.38^{\circ} \mathrm{C}$, in the first scenario, where the cooling capacity is not included and increases to $37.13{ }^{\circ} \mathrm{C}$ in the second scenario. The refrigerant mass flow rate is at its maximum, $12.13 \mathrm{~g} / \mathrm{s}$, in the first scenario, where the cooling capacity is not considered and decreases to $11.05 \mathrm{~g} / \mathrm{s}$ in the second scenario. The discharge temperature and refrigerant mass flow rate are considered in both scenarios. According to TOPSIS results, it can be concluded that the variables have better conditions in the first proposed scenario.

Table 5. Optimum points of the multi-objective optimization by NSGA II.

\begin{tabular}{|c|c|c|c|c|c|c|}
\hline \multicolumn{7}{|c|}{ First scenario } \\
\hline $\mathbf{T}_{\text {evap }}$ & $\mathbf{T}_{\mathbf{c}}$ & SHD & SCD & $\mathbf{P}_{\text {comp }}$ & $\mathbf{T}_{\text {dis }}$ & $\mathbf{m}_{\text {ref }}$ \\
\hline 8.71 & 24.50 & 10.49 & 15.66 & 335.86 & 36.38 & 12.13 \\
\hline-14.83 & 24.51 & 10.49 & 15.64 & 304.05 & 51.47 & 4.33 \\
\hline-14.77 & 27.04 & 11.52 & 15.65 & 364.18 & 64.54 & 4.04 \\
\hline-14.85 & 25.14 & 11.22 & 15.64 & 338.54 & 58.79 & 4.15 \\
\hline 4.36 & 24.56 & 10.51 & 15.65 & 337.53 & 37.88 & 10.33 \\
\hline-6.75 & 24.86 & 10.55 & 15.65 & 330.57 & 45.27 & 6.45 \\
\hline-14.85 & 25.07 & 10.64 & 15.65 & 315.67 & 53.98 & 4.27 \\
\hline-14.69 & 28.34 & 12.36 & 15.65 & 393.86 & 71.74 & 3.89 \\
\hline-4.41 & 24.76 & 10.58 & 15.65 & 334.48 & 43.54 & 7.17 \\
\hline-14.94 & 30.55 & 12.05 & 15.65 & 400.17 & 73.66 & 3.80 \\
\hline-14.99 & 34.87 & 13.36 & 15.66 & 429.51 & 83.56 & 3.58 \\
\hline-14.90 & 34.88 & 13.35 & 15.66 & 429.64 & 83.42 & 3.60 \\
\hline 0.86 & 24.71 & 10.51 & 15.64 & 337.57 & 39.72 & 9 \\
\hline-11.30 & 24.82 & 10.62 & 15.64 & 322.70 & 49.72 & 5.16 \\
\hline 0.88 & 24.93 & 10.64 & 15.65 & 343.84 & 41.16 & 8.95 \\
\hline-2.14 & 24.76 & 10.52 & 15.65 & 335.55 & 41.58 & 7.94 \\
\hline 5.89 & 24.64 & 10.51 & 15.64 & 338.46 & 37.51 & 10.94 \\
\hline-14.95 & 31.28 & 13.12 & 15.65 & 418.36 & 79.45 & 3.67 \\
\hline \multicolumn{7}{|c|}{ Second scenario } \\
\hline $\mathbf{T}_{\text {evap }}$ & $\mathbf{T}_{\mathbf{c}}$ & SHD & SCD & $\mathbf{Q}_{\text {evap }}$ & $\mathbf{T}_{\text {dis }}$ & $\mathbf{m}_{\text {ref }}$ \\
\hline 6.12 & 24.51 & 10.50 & 15.65 & 2143.15 & 37.13 & 11.05 \\
\hline-12.61 & 33.81 & 13 & 15.63 & 679.10 & 78.59 & 4.13 \\
\hline
\end{tabular}




\begin{tabular}{ccccccc}
\hline-3.50 & 24.62 & 10.53 & 15.65 & 1446.13 & 42.21 & 7.49 \\
-1.54 & 25.01 & 10.51 & 15.64 & 1560.71 & 41.73 & 8.13 \\
-14.98 & 34.88 & 13.35 & 15.66 & 576.31 & 83.54 & 3.58 \\
4.42 & 24.60 & 10.54 & 15.62 & 2000.13 & 38.25 & 10.34 \\
-11.89 & 25.12 & 10.62 & 15.63 & 970.27 & 50.98 & 4.99 \\
3.29 & 24.66 & 10.52 & 15.62 & 1913.38 & 38.63 & 9.91 \\
-13.32 & 25.87 & 11.16 & 15.63 & 853.26 & 58.12 & 4.40 \\
-10.32 & 25.03 & 10.63 & 15.63 & 1046.51 & 49.37 & 5.41 \\
-4.74 & 24.90 & 10.56 & 15.64 & 1359.95 & 43.89 & 7.07 \\
1.83 & 24.84 & 10.54 & 15.64 & 1798.50 & 39.74 & 9.34 \\
-13.3 & 27.59 & 11.95 & 15.61 & 773.59 & 66.59 & 4.29 \\
-12.83 & 25.63 & 11.99 & 15.63 & 828.80 & 62.97 & 4.46 \\
-14.63 & 29.82 & 11.72 & 15.64 & 692.24 & 70.42 & 3.94 \\
-14.45 & 34.45 & 13.20 & 15.57 & 600.15 & 82.04 & 3.71 \\
4.94 & 24.54 & 10.58 & 15.62 & 2040.12 & 38.22 & 10.54 \\
\hline
\end{tabular}

\section{Concluding remarks}

In this study, the behavior of R450A in refrigeration systems is comprehensively investigated and subsequently optimized for the first time to reach the maximum performance of the system by defining two different scenarios. Using the experimental data, a hybrid multiobjective optimization model coupling response surface method and non-dominated sorted genetic algorithm II is established. The effects of each input parameters have been illustrated on the $2 \mathrm{D}$ contour plots for each of the optimized parameters, presenting the pairwise comparisons between the variable parameters and indicating eventual optimum operation conditions. TOPSIS decision maker is applied to the Pareto optimal solutions to select the best solution for each case scenario. From the outcome of this research, the following conclusions are drawn:

I. According to the fitted correlations by RSM-CCD, the optimum models for responses are found to be quadratic. All the established quadratic-equation models for responses demonstrate high significance based on p-values with a $95 \%$ confidence level. The values of experimental and estimated are also found to be very close to each other indicating efficiency and favorable performance of the developed models. The corresponding coefficient of determination values for the $\mathrm{P}_{\text {comp }}, \mathrm{Q}_{\text {evap }}, \mathrm{COP}, \mathrm{T}_{\mathrm{dis}}$, and $\mathrm{m}_{\text {ref }}$ are calculated yielding 0.9736 , 0.9994, 0.9989, 0.9932, and 0.9993, respectively. 
II. Analysis of variance indicates that middle condenser temperature with a contribution of $58.86 \%$ is more dominant than the other parameters to affect motor-compressor electrical power consumption. The middle evaporator temperature with a contribution of $94.15 \%$, $87.49 \%, 71.52 \%$, and $96.38 \%$ is identified as one significantly affecting the cooling capacity, coefficient of performance, discharge temperature, and refrigerant mass flow rate, respectively. III. In accordance with the first scenario optimum results, the maximum percentages of reduction in the motor-compressor electrical power consumption and discharge temperature yield $19.72 \%$ and $54.21 \%$, respectively, and the maximum percentage of growth in the refrigerant mass flow rate equals $230.52 \%$ when the middle evaporator temperature, middle condenser temperature, superheating degree, and sub-cooling degree change from $-14.95{ }^{\circ} \mathrm{C}$ to $8.71{ }^{\circ} \mathrm{C}, 31.28{ }^{\circ} \mathrm{C}$ to $24.50{ }^{\circ} \mathrm{C}, 13.12 \mathrm{~K}$ to $10.49 \mathrm{~K}$, and $15.65 \mathrm{~K}$ to $15.66 \mathrm{~K}$, respectively.

IV. In accordance with results obtained via TOPSIS approach, the best optimum point for the first scenario is at a middle evaporator temperature of $8.71{ }^{\circ} \mathrm{C}$, middle condenser temperature of $24.50{ }^{\circ} \mathrm{C}$, superheating degree of $10.49 \mathrm{~K}$, and subcooling degree of operating temperature of $15.66 \mathrm{~K}$. The most optimum result for the second scenario is obtained using a value of middle evaporator temperature of $6.12^{\circ} \mathrm{C}$, middle condenser temperature of $24.51{ }^{\circ} \mathrm{C}$, superheating degree of $10.50 \mathrm{~K}$, and subcooling degree of operating temperature of $15.65 \mathrm{~K}$.

The research results presented in this study can be a useful aid for designers and researchers to select the best design parameters, set up the optimal operating variables, and enhance the performance of the system.

\section{Acknowledgment}

Adrián Mota-Babiloni acknowledges the Spanish Government for the financial support under the grant "Juan de la Cierva-formación 2016" (FJCI-2016-28324). 


\section{References}

Ahmadi, M.H., Ahmadi, M.A., Pourfayaz, F., 2016. Thermodynamic analysis and evolutionary algorithm based on multi-objective optimization performance of actual power generating thermal cycles. Applied Thermal Engineering 99, 996-1005.

Belman-Flores, J.M., Mota-Babiloni, A., Ledesma, S., Makhnatch, P., 2017. Using ANNs to approach to the energy performance for a small refrigeration system working with R134a and two alternative lower GWP mixtures. Applied Thermal Engineering 127, 996-1004.

Bendato, I., Cassettari, L., Mosca, R., Williams, E., Mosca, M., 2017. A stochastic methodology to evaluate the optimal multi-site investment solution for photovoltaic plants. Journal of Cleaner Production 151, 526-536.

Box, G.E.P., Hunter, J.S., 1957. Multi-factor experimental designs for exploring reponse surfaces. Annals of Mathematical Statistics 28, 195-241.

Box, G.E.P., Wilson, K.B., 1951. On the experimental attainment of optimum conditions. Journal of Royal Statistical Society, Series B 13, 1-45.

Buzelin, L.O.S., Amico, S.C., Vargas, J.V.C., Parise, J.A.R., 2005. Experimental development of an intelligent refrigeration system. International Journal of Refrigeration 28, 165-175.

Deb, K., Pratap, A., Agarwal, S., Meyarivan, T., 2002. A fast and elitist multiobjective genetic algorithm: NSGA-II. IEEE Transactions on Evolutionary Computation 6, 182-197.

Devecioğlu, A.G., Oruç, V., 2015. Characteristics of some new generation refrigerants with low GWP. Energy Procedia 75, 1452-1457.

Domanski, P.A., Brignoli, R., Brown, J.S., Kazakov, A.F., McLinden, M.O., 2017. Low-GWP refrigerants for medium and high-pressure applications. International Journal of Refrigeration 84, 198-209.

Esfe, M.H., Hajmohammad, H., Toghraie, D., Rostamian, H., Mahian, O., Wongwises, S., 2017. Multi-objective optimization of nanofluid flow in double tube heat exchangers for applications in energy systems. Energy 137, 160-171.

Goldberg, D.E., 1989. Genetic algorithms in search, optimization and machine learning. Addison-Wesley.

IIR, 2015. The role of refrigeration in the global economy, 29th Informatory Note on Refrigeration Technologies France.

IPCC, 2014. Summary for policymakers, In: Climate Change 2014: Impacts, Adaptation, and Vulnerability., Cambridge University Press, Cambridge, United Kingdom and New York, NY, USA, pp. 1-32.

Jensen, D.R., 1995. Efficiency comparisons of central composite designs. Journal of Statistical Computation and Simulation 52, 177-183.

Kedzierski, M.A., Kang, D., 2018. Horizontal convective boiling of R1234yf, R134a, and R450A within a micro-fin tube. International Journal of Refrigeration 88, 538-551. 
Liu, Y., Liu, L., Liang, L., Liu, X., Li, J., 2015. Thermodynamic optimization of the recuperative heat exchanger for Joule-Thomson cryocoolers using response surface methodology. International Journal of Refrigeration 60, 155-165.

Llopis, R., Sánchez, D., Cabello, R., Catalán-Gil, J., Nebot-Andrés, L., 2017. Experimental analysis of R-450A and R-513A as replacements of R-134a and R-507A in a medium temperature commercial refrigeration system. International Journal of Refrigeration 84, 52-66.

Mahmoudi, B., Naeiji, P., Varaminian, F., Ghazi, M.M., 2016. Statistical optimization of hydrate formation conditions of TBAB and THF mixture as a cold storage material for airconditioning system based on response surface methodology. International Journal of Refrigeration 69, 17-27.

Makela, M., 2017. Experimental design and response surface methodology in energy applications: a tutorial review. Energy Conversion and Management 151, 630-640.

Makhnatch, P., Mota-Babiloni, A., Khodabandeh, R., 2017. Experimental study of R450A drop-in performance in an R134a small capacity refrigeration unit. International Journal of Refrigeration 84, 26-35.

Mamourian, M., Shirvan, K.M., Mirzakhanlari, S., 2016. Two phase simulation and sensitivity analysis of effective parameters on turbulent combined heat transfer and pressure drop in a solar heat exchanger filled with nanofluid by Response Surface Methodology. Energy 109, 4961 .

Mendoza-Miranda, J.M., Mota-Babiloni, A., Navarro-Esbrí, J., 2016a. Evaluation of R448A and R450A as low-GWP alternatives for R404A and R134a using a micro-fin tube evaporator model. Applied Thermal Engineering 98, 330-339.

Mendoza-Miranda, J.M., Mota-Babiloni, A., Ramírez-Minguela, J.J., Muñoz-Carpio, V.D., Carrera-Rodríguez, M., Navarro-Esbrí, J., Salazar-Hernández, C., 2016b. Comparative evaluation of R1234yf, R1234ze(E) and R450A as alternatives to R134a in a variable speed reciprocating compressor. Energy 114, 753-766.

Meyer, R.H., Montgomery, D.C., Anderson-Cook, C.M., 2016. Response surface methodology: process and product optimization using designed experiments, 4th edition. John Wiley \& Sons, Inc. , New York.

Morero, B., Groppelli, E.S., Campanella, E.A., 2017. Evaluation of biogas upgrading technologies using a response surface methodology for process simulation. Journal of Cleaner Production 141, 978-988.

Mota-Babiloni, A., Makhnatch, P., Khodabandeh, R., 2017. Recent investigations in HFCs substitution with lower GWP synthetic alternatives: Focus on energetic performance and environmental impact International Journal of Refrigeration 82, 288-301.

Mota-Babiloni, A., Navarro-Esbri, J., Barragan-Cervera, A., Moles, F., Peris, B., 2015. Experimental study of an R1234ze(E)/R134a mixture (R450A) as R134a replacement. International Journal of Refrigeration 51, 52-58.

Myers, R.H., 1971. Response surface methodology. Allyn and Bacon, Inc. , Boston. 
Myhre, G., Shindell, D., Bréon, F.-M., Collins, W., Fuglestvedt, J., Huang, J., Koch, D., Lamarque, J.-F., Lee, D., Mendoza, B., Nakajima, T., Robock, A., Stephens, G., Takemura, T., Zhang, H., 2013. Anthropogenic and natural radiative forcing, Climate Change 2013: The Physical Science Basis. Contribution of Working Group I to the Fifth Assessment Report of the Intergovernmental Panel on Climate Change. Cambridge University Press, Cambridge, United Kingdom and New York, NY, USA.

Rao, S.S., 1991. Optimization theory and applications. Wiley Eastern Limited, New Delhi.

Simmonds, P.G., Derwent, R.G., Manning, A.J., McCulloch, A., O'Doherty, S., 2015. USA emissions estimates of $\mathrm{CH} 3 \mathrm{CHF} 2, \mathrm{CH} 2 \mathrm{FCF} 3, \mathrm{CH} 3 \mathrm{CF} 3$ and $\mathrm{CH} 2 \mathrm{~F} 2$ based on in situ observations at Mace Head. Atmospheric Environment 104, 27-38.

UNEP, 2016. Report of the twenty-eighth meeting of the parties to the montreal protocol on substances that deplete the ozone layer, Kigali.

Wu, H., Chen, H., Wang, Y., Ding, A., Chen, J., 2018. The changing ambient mixing ratios of long-lived halocarbons under Montreal Protocol in China. Journal of Cleaner Production 188, 774-785. 